\title{
Evaluation of single and multiple Doppler lidar techniques to measure complex flow during the XPIA field campaign
}

\author{
Aditya Choukulkar ${ }^{1,2}$, W. Alan Brewer ${ }^{2}$, Scott P. Sandberg ${ }^{2}$, Ann Weickmann ${ }^{1,2}$, Timothy A. Bonin ${ }^{1,2}$, \\ R. Michael Hardesty ${ }^{1,2}$, Julie K. Lundquist ${ }^{3,4}$, Ruben Delgado ${ }^{5}$, G. Valerio Iungo ${ }^{6}$, Ryan Ashton ${ }^{6}$, Mithu Debnath ${ }^{6}$, \\ Laura Bianco $^{1,7}$, James M. Wilczak ${ }^{7}$, Steven Oncley ${ }^{8}$, and Daniel Wolfe ${ }^{7}$ \\ ${ }^{1}$ Cooperative Institute for Research in Environmental Sciences, Boulder, CO, USA \\ ${ }^{2}$ Chemical Sciences Division, National Oceanic and Atmospheric Administration, Boulder, CO, USA \\ ${ }^{3}$ Department of Atmospheric and Oceanic Sciences, University of Colorado Boulder, CO, USA \\ ${ }^{4}$ National Renewable Energy Laboratory, Golden, CO, USA \\ ${ }^{5}$ Atmospheric Physics Department, University of Maryland Baltimore County, MD, USA \\ ${ }^{6}$ Department of Mechanical Engineering, University of Texas at Dallas, Richardson, TX, USA \\ ${ }^{7}$ Physical Sciences Division, National Oceanic and Atmospheric Administration, Boulder, CO, USA \\ ${ }^{8}$ National Center for Atmospheric Research, Boulder, CO, USA
}

Correspondence to: Aditya Choukulkar (aditya.choukulkar@noaa.gov)

Received: 1 October 2016 - Published in Atmos. Meas. Tech. Discuss.: 10 October 2016

Revised: 21 December 2016 - Accepted: 22 December 2016 - Published: 23 January 2017

\begin{abstract}
Accurate three-dimensional information of wind flow fields can be an important tool in not only visualizing complex flow but also understanding the underlying physical processes and improving flow modeling. However, a thorough analysis of the measurement uncertainties is required to properly interpret results. The XPIA (eXperimental Planetary boundary layer Instrumentation Assessment) field campaign conducted at the Boulder Atmospheric Observatory (BAO) in Erie, CO, from 2 March to 31 May 2015 brought together a large suite of in situ and remote sensing measurement platforms to evaluate complex flow measurement strategies.

In this paper, measurement uncertainties for different single and multi-Doppler strategies using simple scan geometries (conical, vertical plane and staring) are investigated. The tradeoffs (such as time-space resolution vs. spatial coverage) among the different measurement techniques are evaluated using co-located measurements made near the BAO tower. Sensitivity of the single-/multi-Doppler measurement uncertainties to averaging period are investigated using the sonic anemometers installed on the BAO tower as the standard reference. Finally, the radiometer measurements are used to partition the measurement periods as a function of atmospheric
\end{abstract}

stability to determine their effect on measurement uncertainty.

It was found that with an increase in spatial coverage and measurement complexity, the uncertainty in the wind measurement also increased. For multi-Doppler techniques, the increase in uncertainty for temporally uncoordinated measurements is possibly due to requiring additional assumptions of stationarity along with horizontal homogeneity and less representative line-of-sight velocity statistics. It was also found that wind speed measurement uncertainty was lower during stable conditions compared to unstable conditions.

\section{Introduction}

Scanning coherent Doppler light detection and ranging (lidar) systems have proven to be invaluable tools for wind measurements in research as well as commercial applications. A valuable advantage of scanning Doppler lidar systems is its ability to make measurements over horizontal and vertical extents using a combination of azimuthal, plan position indicator (PPI) scans and vertical plane (RHI) scans. Doppler lidars measure the projection of the wind velocity along the beam pointing direction denoted as line-of- 
sight (LOS) velocity or radial velocity given in Eq. (1).

$V_{r}=u \sin \theta \cos \phi+v \cos \theta \cos \phi+w \sin \phi$,

where $V_{r}$ is the LOS velocity, $u, v, w$ are the velocity components in the east-west direction, the north-south direction, and in the vertical, respectively, and $\theta$ and $\phi$ are the azimuth and elevation angles, respectively. In order to derive the twodimensional (2-D) or three-dimensional (3-D) wind velocity the use of suitable measurement strategies and/or velocity retrieval algorithms is required.

The 2-D and 3-D wind measurements from Doppler lidars are useful in various fields of study such as boundary layer meteorology (Fernando et al., 2015; Vanderwende et al., 2015), air quality (Barlow et al., 2011; Collier et al., 2005), wind energy research (Banta et al., 2015; Käsler et al., 2010; Mikkelsen, 2014; Newsom et al., 2015) and others. The simplest techniques to derive a profile of wind speed and direction using a single-Doppler lidar are the velocity azimuth display (VAD) technique (Browning and Wexler, 1968) and the Doppler beam swinging (DBS) technique (Strauch et al., 1984). These techniques assume horizontal homogeneity of the wind in the measurement volume to estimate the profile of wind speed and direction. Other techniques such as the velocity volume processing (Waldteufel and Corbin, 1979) and the "arc scan" technique (Wang et al., 2015) limit the assumption of horizontal homogeneity to smaller volumes within the lidar scans or to certain azimuth ranges, respectively, allowing one to better preserve the spatial variability information at the expense of increased uncertainty in the wind retrieval, especially when the wind direction is perpendicular to the scan sector (Krishnamurthy et al., 2013).

A common method to make wind-field measurements without assumption of spatial homogeneity is through multiDoppler techniques. "Virtual towers" (Calhoun et al., 2006) use multiple Doppler lidars to interrogate a common volume in space in a temporally coordinated fashion, iterating through several height in order to create a wind profile. Several configurations of multi-Doppler scanning have been tested to quantify the skill in deriving 2-D and 3-D wind fields. For example, co-planar RHI scans were used to study flows in mountain valleys (Hill et al., 2010) and within a meteor crater (Cherukuru et al., 2015), and co-planar conical scans (PPIs) have been used to study coherent structures (Newsom et al., 2008; Träumner et al., 2015) and wind turbine wakes (Vollmer et al., 2015). Three-dimensional wind-field measurements made using dual-Doppler intersecting RHI scans and using continuity to estimate the vertical velocity were used to study flow upstream and downstream of a utility-scale wind turbine (Newsom et al., 2015). Three-dimensional wind and turbulence measurements using fully coordinated short-range continuous wave triple lidars (Mikkelsen et al., 2008; Simley et al., 2016) and long-range triple lidar scanning (Berg et al., 2015; Vasiljević et al., 2016) have been demonstrated to provide high quality measurements of complex flow. In addition, manually coordinated triple lidar measurements (Wang et al., 2016) were also tested and showed promise in measuring the 3-D wind fields operationally. The Lower Atmospheric Boundary Layer Experiment (LABLE) validated wind and turbulence measurements from triple-Doppler lidar measurements (Klein et al., 2015; Newman et al., 2016).

In addition to multi-Doppler approaches to measuring complex flow, several techniques enable wind-field retrievals from single-Doppler lidars, which resolve the spatial variability measured by the lidar. For example, the optimal interpolation (OI) technique allows 2-D wind-field retrievals on azimuthal scans (Choukulkar et al., 2012) without assumption of homogeneity of the wind field. In addition, variational methods can determine the wind fields from single or multiple Doppler lidars (Chan and Shao, 2007; Drechsel et al., 2009; Newsom et al., 2008).

The choice of the measurement strategy and the retrieval algorithms comes with assumptions inherent to their process which need to be properly understood to interpret the measurements made. Several studies have been conducted to evaluate the measurement accuracy of the various single and multi-Doppler techniques. For example, measurement uncertainties in wind measurements made using the DBS technique in complex terrain were investigated by Bingöl et al. (2009) while Lundquist et al. (2015) studied the uncertainties in wind measurements using the DBS technique in presence of complex flow by simulating lidar measurements within a wind turbine wake using a wind field created with large-eddy simulation. Wind-field measurements made using the virtual tower technique have been validated (Damian et al., 2014; Gunter et al., 2015) to show high skill in measuring 2-D wind fields and Stawiarski et al. (2013) did a detailed error analysis of dual Doppler co-planar PPI technique. Uncertainties in 3-D wind-field retrievals using triple-Doppler lidar techniques have also been investigated. For example, Mann et al. (2009), Fuertes et al. (2014) and Newman et al. (2016) present a detailed analysis of 3-D winds and turbulence measurements made using staring triple-Doppler measurements, while Berg et al. (2015) present validation of 3-D wind measurements made through continuous scanning.

While considerable effort has been devoted to evaluating each of these wind measurement techniques, few studies have intercompared wind measurements from multiple Doppler lidar techniques against a common standard or discussed the tradeoffs between the different measurement techniques in terms of time and space resolution, ability to resolve spatial variability and spatial coverage. The eXperimental Planetary boundary layer Instrumentation Assessment (XPIA) field campaign conducted at the Boulder Atmospheric Observatory (BAO) in Erie, $\mathrm{CO}$, from 2 March to 31 May 2015 provided a unique opportunity to intercompare (in similar atmospheric conditions) various single- and multiDoppler wind measurement strategies to measure complex flow. In this paper, precision of single- and multiple-Doppler lidar techniques to measure complex flow is evaluated. In 


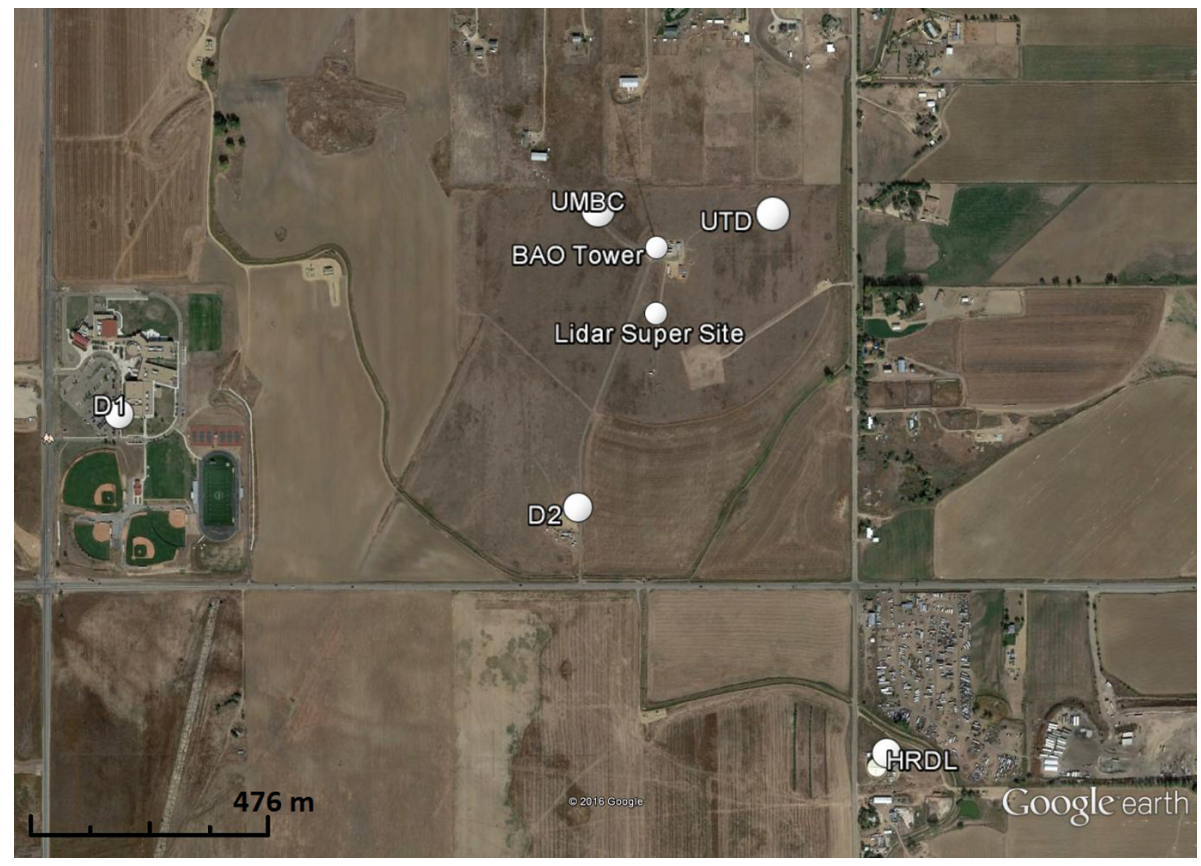

Figure 1. Scanning Doppler lidar deployment location during the XPIA field campaign.

addition, the tradeoffs in terms of measurement precision, spatial coverage and temporal resolution between the various measurement techniques are also discussed. The measurement techniques discussed in this paper are limited to using simple scan geometries such PPI, RHI and stare scans. However, as most commercially available lidar systems are limited to performing these scan modes, this paper discusses the possibilities available to such lidar systems. The paper is organized as follows: the experiment setup and measurement area is described in Sect. 2. Section 3 presents analysis of the LOS velocity uncertainty and Sect. 4 presents results from the validation of the different measurement techniques tested in XPIA. This is followed by a discussion of the results in Sect. 5. Concluding remarks are presented in Sect. 6.

\section{Experiment setup}

The XPIA field study, funded by the US Department of Energy (DOE) within the Atmosphere to electrons (A2e) program, had the goal to assess current capabilities for measuring complex flow in and near wind farms using remote sensing instrumentation. With this goal in mind, a large suite of instrumentation was deployed near the BAO (Kaimal and Gaynor, 1983) facility in Erie, CO. The instrumentation included six scanning Doppler lidars (four capable of coordinated scanning) and five vertically profiling lidars. Lundquist et al. (2016a) give a detailed description of the XPIA field study along with an overview of the instrumentation deployment. Herein, for sake of brevity, only the details of the scanning lidar deployment used for testing the various sin- gle and multi-Doppler measurements are described. These lidars included two Leosphere 200S ${ }^{\circledR}$ scanning lidars (named D1 and D2) and the high-resolution Doppler lidar (HRDL) from the National Oceanic and Atmospheric Administration (NOAA), one Leosphere $200 \mathrm{~S}^{\circledR}$ scanning Doppler lidar from the University of Texas at Dallas (UTD) and one Leosphere $200 \mathrm{~S}^{\circledR}$ from the University of Maryland Baltimore County (UMBC). Figure 1 shows the deployment locations of these scanning lidars with respect to the $300 \mathrm{~m}$ tall instrumented BAO tower. The pulse width and time accumulation for each of the lidars used in the analysis presented in this paper is given in Table 1. All the wind measurement comparisons presented in this paper are with respect to the measurements made by the southeast sonic anemometers installed on the BAO tower as the center of the lidar measurement volume (and the range gates) were always south of the BAO tower. The sonic anemometer data are filtered to remove tower wake effects using the criteria defined in McCaffrey et al. (2016).

During the initial stages of the experiment, all the scanning Doppler lidars described above were tested for scanner pointing accuracy. For lidars involved in coordinated scanning (D1, D2 and UTD), the repeatability as well as accuracy of pointing and reproducibility of time synchronization were tested. The details of these tests and the results are described in detail by Lundquist et al. (2016b) and summarized in Table 2. The scan initialization delay estimates from time synchronization tests for the lidars involved in coordinated scanning are summarized in Table 3. The scan initialization delay is defined as the time delay between the desired scan start time and the actual scan start time. In addition to the 
Table 1. Lidar operational parameters.

\begin{tabular}{lrr}
\hline Lidar & $\begin{array}{r}\text { Pulse width } \\
(\mathrm{m})\end{array}$ & $\begin{array}{r}\text { Time accumulation } \\
(\mathrm{s})\end{array}$ \\
\hline HRDL & 30 & 0.5 \\
D1 & 50 & 0.5 \\
D2 & 50 & 0.5 \\
UTD & 50 & 0.5 \\
UMBC & 50 & $1^{*}$ \\
* Longer accumulation time was selected to ensure sufficient \\
range (and hence coverage) during uncoordinated volume \\
scans.
\end{tabular}

Table 2. Scanner pointing accuracy and repeatability estimates for the scanning Doppler lidars.

\begin{tabular}{lrrr}
\hline Lidar & $\begin{array}{r}\text { Pointing } \\
\text { error }\left(^{\circ}\right)\end{array}$ & $\begin{array}{r}\text { Repeatability } \\
\text { in AZ }\left(^{\circ}\right)\end{array}$ & $\begin{array}{r}\text { Repeatability } \\
\text { in EL }\left(^{\circ}\right)\end{array}$ \\
\hline HRDL & $<0.1$ & $\sim 0.05$ & $\sim 0.05$ \\
D1 & $\sim 0.15$ & 0.01 & 0.05 \\
D2 & $\sim 0.15$ & 0.01 & 0.05 \\
UTD & $\sim 0.15$ & Not determined & Not determined \\
UMBC & $\sim 0.15$ & Not determined & Not determined \\
\hline
\end{tabular}

scan initialization delay, the delay introduced due to each of the lidars scanning varying range of azimuths to reach the measurement location was characterized and accounted for during the scan strategy design for each of the measurement techniques evaluated. The net impact of all the pointing and time synchronization uncertainties is that all the systems could make measurements at a prescribed location at a given time with pointing uncertainty of less than $0.15^{\circ}$ (approximately $\pm 2.5 \mathrm{~m}$ at $1 \mathrm{~km}$ range) and time uncertainty of less than $0.4 \mathrm{~s}$.

In this paper, the following Doppler lidar measurement techniques will be discussed:

1. coordinated triple-Doppler virtual tower stares (VTS),

2. coordinated triple-Doppler sparse sampling scans,

3. uncoordinated triple-Doppler virtual tower,

4. uncoordinated multi-Doppler volume scan and

5. single-Doppler lidar wind retrieval using the optimal interpolation (OI) technique.

\subsection{Coordinated triple-Doppler virtual tower stares}

The coordinated VTS scan pattern involves interrogating a common volume using multiple Doppler lidars at pre-defined heights at a given location to form a "virtual tower" (Calhoun et al., 2006; Mann et al., 2009; Fuertes et al., 2014; Gunter et al., 2015; Newman et al., 2016). A schematic of
Table 3. Scan initialization delay estimates for the scanning Doppler lidars.

\begin{tabular}{lrr}
\hline Lidar & $\begin{array}{r}\text { Scan initialization } \\
\text { delay (s) }\end{array}$ & $\begin{array}{r}\text { SD of the } \\
\text { delay (s) }\end{array}$ \\
\hline HRDL & $43.28^{\mathrm{a}}$ & 0.42 \\
D1 & 3.98 & 0.29 \\
D2 & 3.81 & 0.3 \\
UTD & 0.79 & 0.3 \\
UMBC & Not applicable & Not applicable \\
\hline a The unusually long delay is due to the automatic scanner \\
calibration routine run at the beginning of each scan cycle. \\
b This system did not have ability to trigger scans at prescribed \\
times.
\end{tabular}

the triple lidar VTS scan tested during the XPIA field experiment is shown in Fig. 2a. Each of the three 200S lidars (D1, D2 and UTD) performed a temporally correlated $25 \mathrm{~s}$ stare at each of the six sonic anemometer levels (50 to $300 \mathrm{~m}$ with $50 \mathrm{~m}$ increments) and therefore creating a virtual tower of wind measurements every $3 \mathrm{~min}$. The LOS velocities that fall within the common volume are least-squares fitted using Eq. (1) (Fuertes et al., 2014) to estimate the 3-D wind velocity.

The common volume is defined as a square (cyan box in Fig. $2 \mathrm{~b}), 35 \mathrm{~m}$ on a side and $10 \mathrm{~m}$ in the vertical centered at each of the sonic height levels with its center $10 \mathrm{~m}$ south of the southeast sonic anemometer on the BAO tower (this was the closest position to the tower that allowed overlapping measurements without blockage). As observed from Fig. $2 b$, the effective measurement volume (defined as the circle enveloping the outermost range-gate points) is slightly larger with a diameter of $60 \mathrm{~m}$. It is also seen from Fig. $2 \mathrm{~b}$ that the look directions of D1 and UTD are close to $180^{\circ}$ apart. This non-ideal setup for triple-Doppler measurements was dictated by logistics of deployment. However, the UTD lidar makes measurements with much steeper elevation angles compared to D1 and hence does provide additional information for wind retrieval.

Similar virtual towers were performed at two other locations to compare with other instrumentation deployed during XPIA. Therefore the repeat period for these virtual towers discussed here is once every $10 \mathrm{~min}$. The $25 \mathrm{~s}$ stare period was chosen to ensure that all three 200S lidars were measuring the common volume simultaneously. However, the 3-D wind retrieval was made using $5 \mathrm{~s}$ of spatially and temporally overlapping LOS velocity data.

\subsection{Coordinated triple-Doppler sparse sampling}

While VTS scan provides a profile of wind velocity at any given location, wind velocity measurements can also be performed over horizontal planes through temporally and spatially coordinated scans that interrogate common volumes on a horizontal plane. One limitation to making measurements 

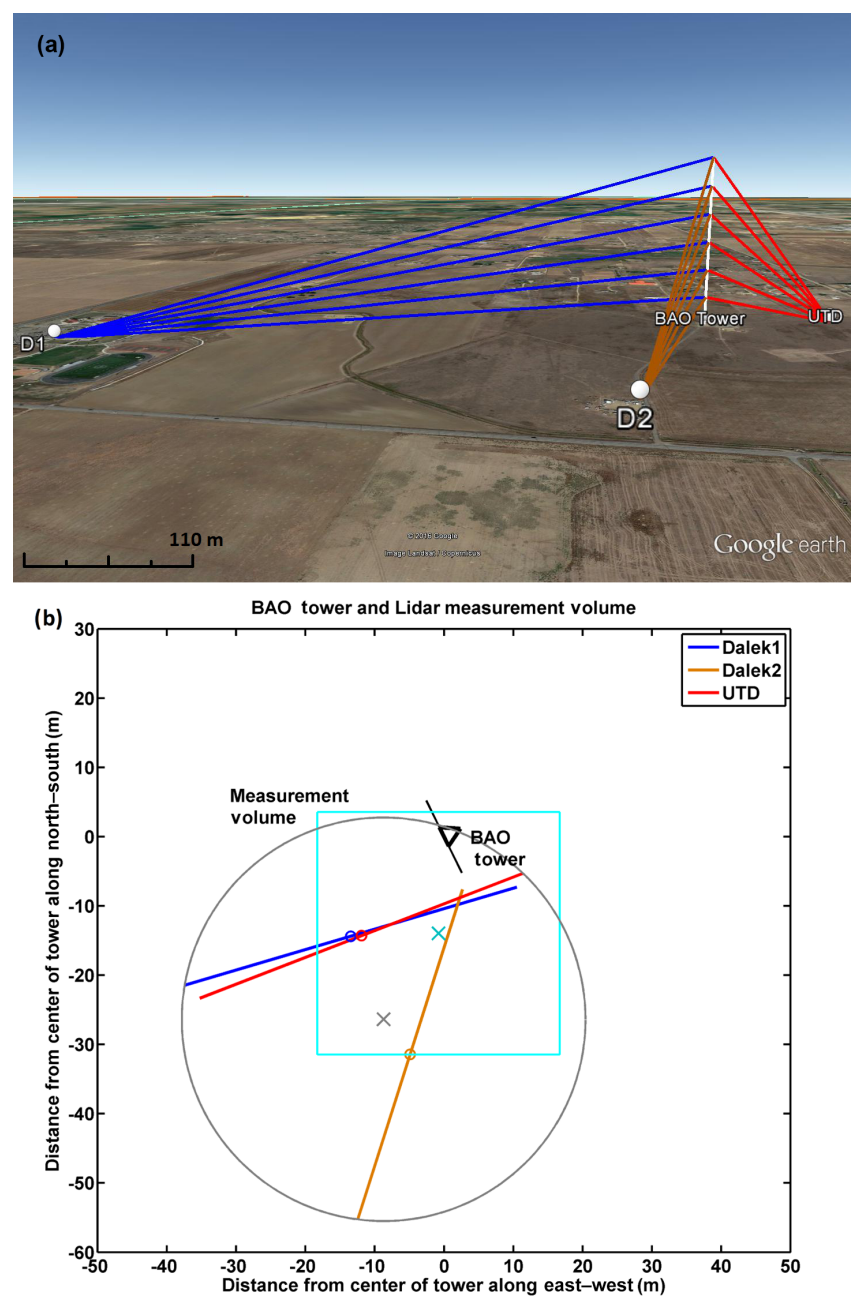

Figure 2. The virtual tower stare (VTS) scan. (a) Schematic of the VTS technique. The blue, red and orange lines indicate beams from each of the three 200S lidars that make measurements at each sonic anemometer level. (b) Location and size of the common volume (cyan box) with respect to the BAO tower. The blue, red and orange lines are range gates from the three 200S lidars that fall within the common volume. The grey circle indicates the estimated measurement volume defined by the position of the range gates.

over a large enough area using contiguous volumes is the time required to simultaneously interrogate this area using coordinated scanning. The time required to complete a scan is determined by the data rate of the lidar systems, overlap period and the geometry defined by the instrument locations. Given the instrument locations during XPIA and data rate limitations of the 200S lidars, the time required to sample an area through contiguous measurement points would be too long to sample a feature sufficiently before it advected out of the measurement domain. Therefore, to reduce the time required to make such a measurement, sparse sampling strategies were considered. The sparse sampling technique discussed in this paper is called small checkerboard (SCB) scan and the layout of this technique is shown in Fig. 3. The scanning strategy involved sampling a $3 \times 3$ grid covering a horizontal area of approximately $150 \mathrm{~m} \times 150 \mathrm{~m}$ and $100 \mathrm{~m}$ above the ground. The three lidars paused $5 \mathrm{~s}$ at each grid point and hence completed one SCB scan every $1 \mathrm{~min}$. This measurement strategy was carried out using the D1, D2 and UTD scanning 200S lidars for a period of 9 days.

\subsection{Uncoordinated triple-Doppler virtual tower}

This measurement technique is similar to the one explained in Sect. 2.1 in that three Doppler lidars scan a common volume to make 3-D wind-field measurements. However, in order to reduce the time required to perform a virtual tower and increase the update rates, the lidars performed continuous temporally uncoordinated RHI scans at the BAO tower location. Each RHI scan takes $15 \mathrm{~s}$ to perform and hence a 3 -D wind-field measurement can be made every $15 \mathrm{~s}$, compared to $3 \mathrm{~min}$ required for the VTS technique. The tradeoff is that not all lidars are looking at the same volume simultaneously. The 3-D wind field is estimated by least-squares fitting to Eq. (1) the LOS velocity measurements from the three 200S lidars (D1, D2 and UTD) that fall within the common volume (50 m on a side and $10 \mathrm{~m}$ in the vertical) and within a $15 \mathrm{~s}$ time window. The three $200 \mathrm{~S}$ lidars performed intersecting RHI scans at three locations (including near the BAO tower) for $20 \mathrm{~min}$ at each location before repeating the sequence again. This measurement strategy was performed for a period of approximately 2 days.

\subsection{Uncoordinated multi-Doppler volume scan}

With the uncoordinated multi-Doppler measurement technique, the constraint that multiple lidars need to interrogate a common volume simultaneously is removed allowing to speed up sampling of the domain of interest. In this measurement technique, five Doppler lidars (HRDL, D1, D2, UTD and UMBC) performed a set of complementary PPI scans that would ensure that at least two Doppler beams overlapped within each grid point (defined as $50 \mathrm{~m}$ on a side in the horizontal and $15 \mathrm{~m}$ in the vertical) within a 5 min update period. This scan strategy resulted in a grid which approximately $1.5 \mathrm{~km} \times 1 \mathrm{~km}$ in the horizontal and covered heights $30 \mathrm{~m}$ to $300 \mathrm{~m}$ above the ground with $15 \mathrm{~m}$ vertical resolution. A representation of the scans performed by each of the scanning lidars and the resulting grid is shown in Fig. 4.

An important consideration in the scan design for this experiment was the limitations on lidar siting and ensuring overlap with the BAO in order to validate the wind measurements. This constraint resulted in the measurement volume being quite close to the Doppler lidars and hence required steep elevation angles and several PPI sectors to cover the volume of interest. These considerations resulted with the spatial coverage and the update rates reported in this paper. Ideally, this type of measurement would be performed with 


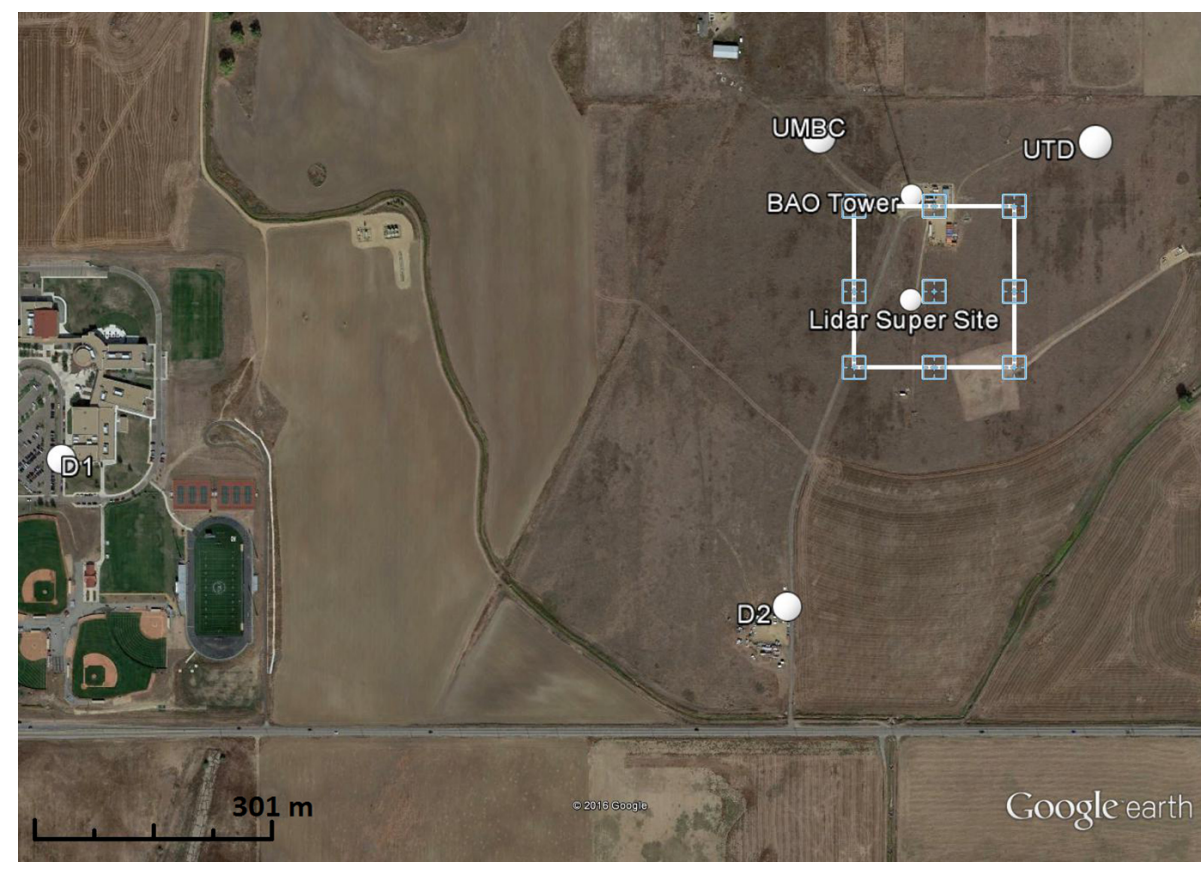

Figure 3. Schematic of the small checkerboard (SCB) scan. The white outline shows the domain over which measurements are made and the blue squares indicate the locations of measurement volumes interrogated by the scanning Doppler lidars.

the Doppler lidars further away from the domain of interest so that shallower elevation PPI scans can be employed which can help cover larger areas with faster update rates.

\subsection{Single-Doppler velocity retrievals}

The single-Doppler retrieval technique investigated in this paper is the OI technique (Choukulkar et al., 2012). The OI technique allows retrieval of 2-D wind fields over PPI scans without assumption of spatial homogeneity of the wind field. The spatial variability information in the LOS velocity field is thus preserved which can be useful to study complex flows such as flow in and near wind farms and in complex terrain. An example retrieval of the horizontal wind field using this technique is shown in Fig. 5.

The OI technique uses Bayesian statistical technique to find a 2-D wind field most consistent with the LOS velocity observations from the lidar PPI scans. The technique starts with a first guess (referred to as "background") of the wind field which is a single VAD estimate using all the LOS velocities from the PPI scan. The final wind field is arrived at by adding an "analysis increment" to the first guess which is estimated using the background and observation error covariances (see Choukulkar et al., 2012, for details). The OI technique does not make any assumptions about the flow field (such as homogeneity or isotropy), however, it assumes that the background error is homogeneous. The validity of this assumption has been tested through simulated lidar measurements and was found to be reasonable (Choukulkar, 2013).
Table 4. Comparison of the instantaneous lidar LOS measurement to sonic-derived LOS measurement at all sonic levels.

\begin{tabular}{lrrrr}
\hline Lidar & Corr. coeff. & Slope & Offset & $\begin{array}{r}\text { SD of } \\
\text { differences }\end{array}$ \\
\hline D1 & 0.99 & 1.01 & $0.02 \mathrm{~m} \mathrm{~s}^{-1}$ & $0.50 \mathrm{~m} \mathrm{~s}^{-1}$ \\
D2 & 0.98 & 0.98 & $-0.12 \mathrm{~m} \mathrm{~s}^{-1}$ & $0.66 \mathrm{~m} \mathrm{~s}^{-1}$ \\
UTD & 0.99 & 1.00 & $-0.60 \mathrm{~m} \mathrm{~s}^{-1}$ & $0.53 \mathrm{~m} \mathrm{~s}^{-1}$ \\
\hline
\end{tabular}

\section{Determining baseline uncertainty}

Uncertainties emerge associated with the LOS velocity measurements made by the Doppler lidar. These uncertainties can be categorized into (1) random error in the estimation of the velocity and (2) error due to the path integration (rangegating) inherent in pulsed Doppler lidar measurements. The random component of the LOS velocity estimate, for D1, found by linearly fitting the autocovariance of the LOS velocity from lags 1 through 4 and extrapolating to zeroth lag (Lenschow et al., 2000) is shown in Fig. 6. Similar values were estimated for all three 200S lidars (D1, D2 and UTD) and the error was a function of signal-to-noise ratio only.

In addition to the uncertainty due to the random noise in the LOS velocity estimates, a systematic underestimation of the variability in the velocity field at shorter length scales is introduced due to the path averaging of the lidar pulse. To determine the additional uncertainty due to range-gate averaging, the power spectrum of the lidar LOS velocity 

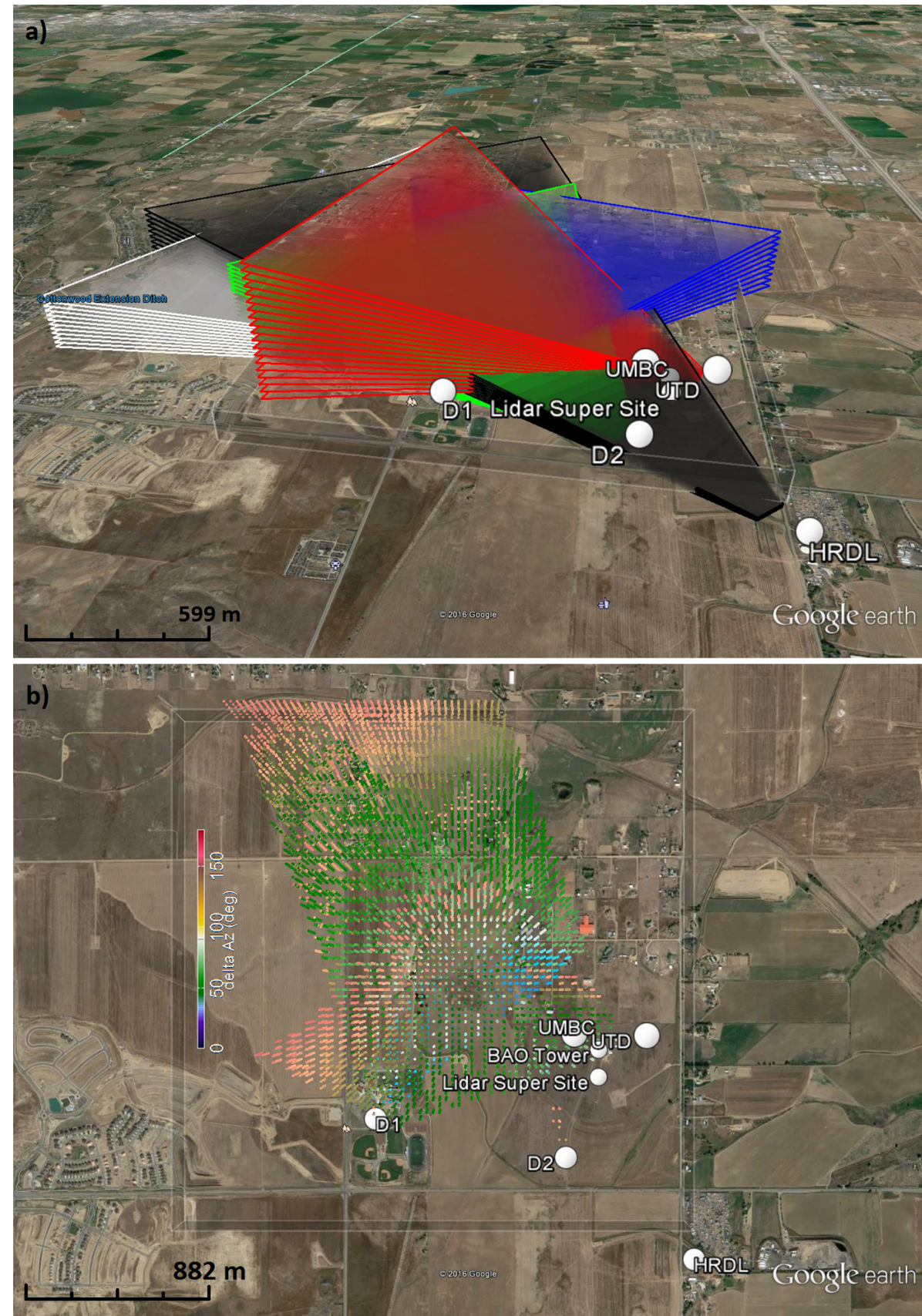

Figure 4. Scans performed by each of the scanning Doppler lidars to produce a 3-D volume of horizontal wind field. (a) Representation of the PPI sector scans performed by each lidar. (b) Grid points that have LOS velocities from at least two lidars and the colors indicate difference in azimuth between their respective look directions.

Table 5. Statistics from comparison of wind-field measurements from the VTS to the sonic anemometer measurements.

\begin{tabular}{lrrrr}
\hline Wind field & Corr. coeff. & Slope & Offset & SD of differences \\
\hline Horizontal wind speed (all heights) & 0.97 & 0.96 & $0.21 \mathrm{~m} \mathrm{~s}^{-1}$ & $0.50 \mathrm{~m} \mathrm{~s}^{-1}$ \\
Horizontal wind direction (all heights) & 0.99 & 0.97 & $3.36^{\circ}$ & $9.87^{\circ}$ \\
Vertical velocity (150-300 m) & 0.86 & 1.06 & $-0.02 \mathrm{~m} \mathrm{~s}^{-1}$ & $0.50 \mathrm{~m} \mathrm{~s}^{-1}$ \\
\hline
\end{tabular}



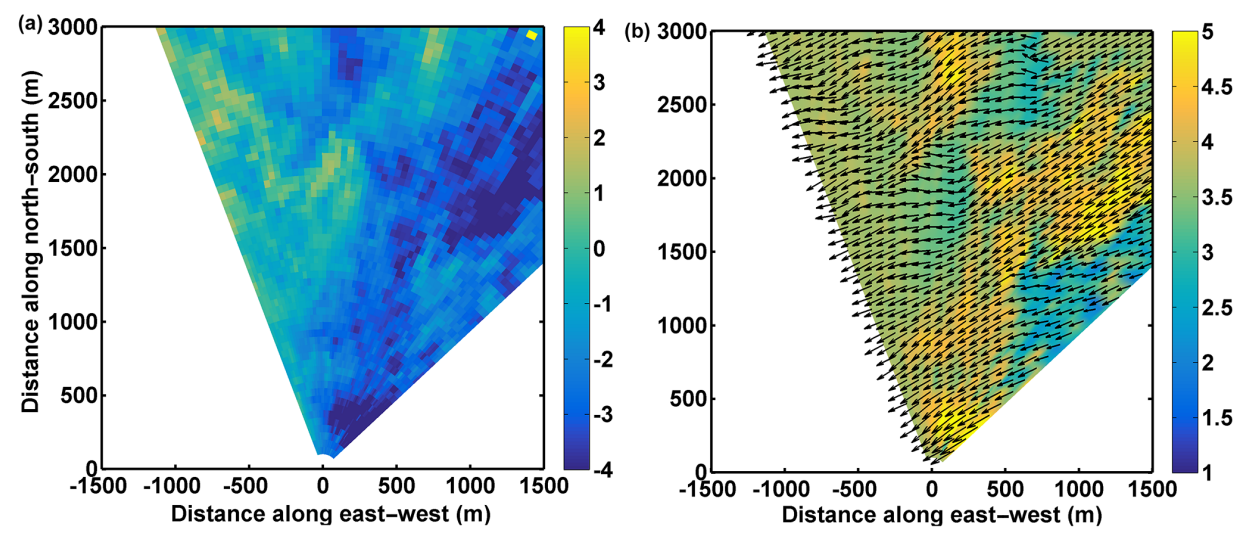

Figure 5. OI retrieval of the horizontal wind field on a PPI scan performed by D1 on 25 April, 16:52 UTC. (a) LOS velocity field (in $\mathrm{m} \mathrm{s}^{-1}$ ) measured by D1. (b) Horizontal wind field retrieved using the OI technique. The colors indicate magnitude of horizontal wind speed (in $\mathrm{m} \mathrm{s}^{-1}$ ) and wind direction is indicated by arrows.

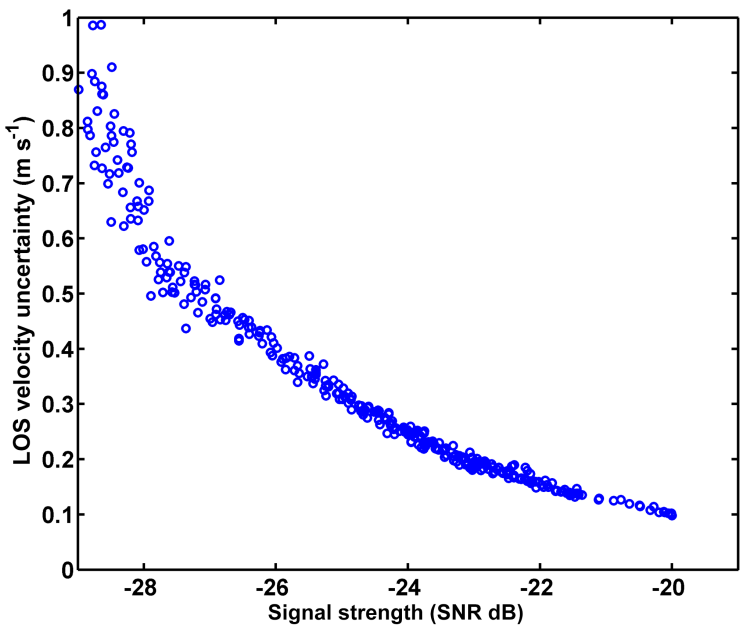

Figure 6. Estimate of the standard deviation of random error as a function of signal-to-noise ratio estimated using Lenschow et al. (2000).

measurements was compared to the power spectrum of the sonic-derived LOS measurements. Data from a 3-day period where the 200S lidars (D1, D2 and UTD) were performing hour long stares at each sonic anemometer level were used. The spectra of the lidar LOS velocity measurements from the various hour long stares at each sonic anemometer level were averaged and compared to correspondingly averaged sonic-derived LOS measurements (see Fig. 7a). As seen in Fig. 7a, the spectra from the lidar LOS measurements (blue line) flattens out for frequencies higher than $\sim 0.25 \mathrm{~Hz}$, indicating that the variations due to random noise dominate. Once the variations due to random noise are subtracted from the spectra, the underprediction of the variability due to the pulse averaging is clearly visible and can be estimated (see Fig. 7b). This underestimation of the variability is defined as the square root of the difference between the spectra of the sonic anemometer and the lidar measurement and is found to be $0.23 \mathrm{~m} \mathrm{~s}^{-1}$. The underestimation of the variability can be interpreted as a smoothing of the lidar measurements and hence adds to the differences between the lidar and sonic anemometer wind measurements.

Finally, the total difference between the $1 \mathrm{~Hz}$ lidarmeasured LOS velocity and the $1 \mathrm{~Hz}$ sonic-derived LOS velocity measurements, as estimated from direct comparison is presented in Table 4 (Lundquist et al., 2016b). This difference is slightly larger than the combined uncertainties from random noise and pulse averaging. This difference in the uncertainty estimates could be due to some factors that are as yet unaccounted or due to improper estimate of the uncertainties due to random noise and pulse averaging. The uncertainty of the LOS measurement by the lidar (when compared to the sonic anemometer) allows evaluating the various measurement techniques in terms of additional uncertainty added to this baseline value. The offset in the LOS velocity of the UTD lidar was found to be due to improper calibration of the pulse-length-dependent frequency offset (Lundquist et al., 2016a). This was characterized using independent measurements and was found to be constant throughout the XPIA campaign. Therefore, in all measurements presented in this paper, this static offset has been subtracted from the UTD lidar LOS velocity.

\section{Validation of wind-field measurements}

The wind-field measurements from the measurement techniques outlined earlier are now evaluated using the sonic anemometer as the standard. A three-step $6 \sigma$ outlier rejection is applied in each of the comparisons before estimating the validation metrics. The validation metrics used here are the mean and standard deviation of the differences between the lidar and sonic anemometer measurements. 

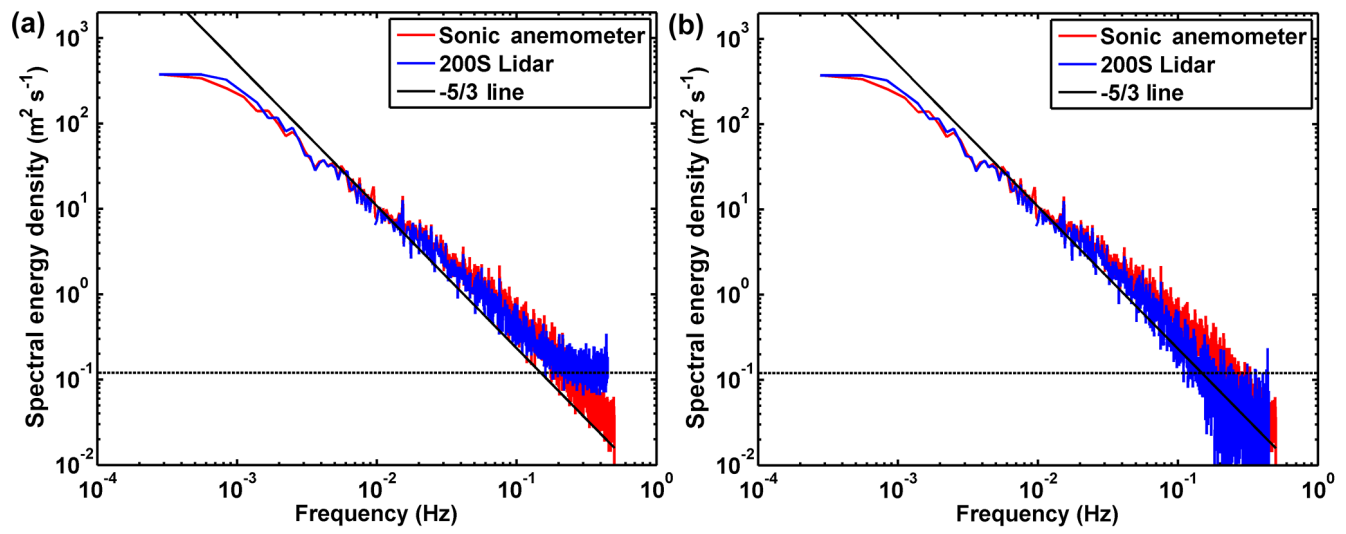

Figure 7. Comparison of the spectra of LOS data measured by the lidar and the LOS derived from the sonic anemometer measurements. The solid black line indicates the energy cascade following the $-5 / 3$ Kolmogorov energy spectrum. (a) Comparison of the spectra showing the noise floor of the Doppler lidar measurements (dotted black line). (b) Comparison of the spectra after subtracting the noise from the lidar spectra. The underprediction of the variability due to the pulse averaging can be seen clearly and found to be $0.23 \mathrm{~m} \mathrm{~s}^{-1}$.
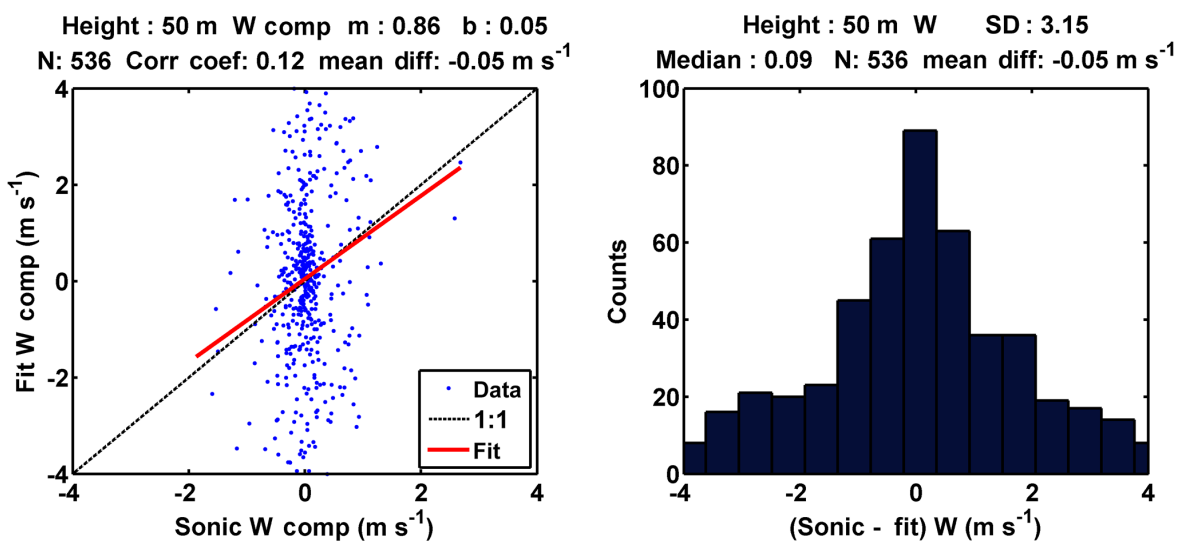

Figure 8. Comparison of the vertical velocity measurements from VTS at the $50 \mathrm{~m}$ level with the sonic anemometer measurements.

\subsection{Virtual tower stares}

The 3-D wind was measured using the VTS technique by taking $5 \mathrm{~s}$ of LOS velocity data from the three 200 S lidars which overlapped in time and space (as defined by the common volume) and least-squares fitted to Eq. (1) to derive the 3-D wind field. The comparisons of the 3-D wind field as measured by the VTS technique to $5 \mathrm{~s}$ averaged sonic anemometer measurements are shown in Table 5. These measurements agree with a high correlation coefficient $(0.97$ and 0.99 for wind speed and direction, respectively) and low standard deviation of the differences $\left(0.51 \mathrm{~m} \mathrm{~s}^{-1}\right.$ and $10.16^{\circ}$ for horizontal wind speed and horizontal wind direction, respectively) between the sonic anemometer and the VTS measurements. In addition, the vertical velocity measurements also show a reasonably good correlation coefficient (0.86) and low standard deviation of differences $\left(0.5 \mathrm{~m} \mathrm{~s}^{-1}\right)$. Note that in the vertical velocity comparisons, only measurements at and above the $150 \mathrm{~m}$ sonic are compared. This is due to the fact that at the lower sonic levels, the elevation angles in the VTS scans were quite low and as a result the component we are trying to estimate is perpendicular to the lidar look direction, resulting in a noisy vertical velocity retrieval. The velocity retrievals at the $50 \mathrm{~m}$ level from the VTS scans are shown in Fig. 8. As can be observed from Fig. 8, there is no skill in the vertical velocity retrievals at low elevation angles.

\subsection{Coordinated sparse sampling}

The comparison of the SCB measurement point over the BAO tower with $15 \mathrm{~s}$ averaged sonic anemometer measurements at the $100 \mathrm{~m}$ level are shown in Fig. 9. The measurements made from the SCB technique show good agreement with sonic anemometer measurements (as shown in Fig. 9) with correlation coefficient of 0.98 and 0.99 for wind speed and wind direction, respectively. The correlation coefficient for the vertical velocity was lower (0.54) due to the fact that these measurements were made at the $100 \mathrm{~m}$ level, which leads to lower skill in vertical velocity measurements as ex- 

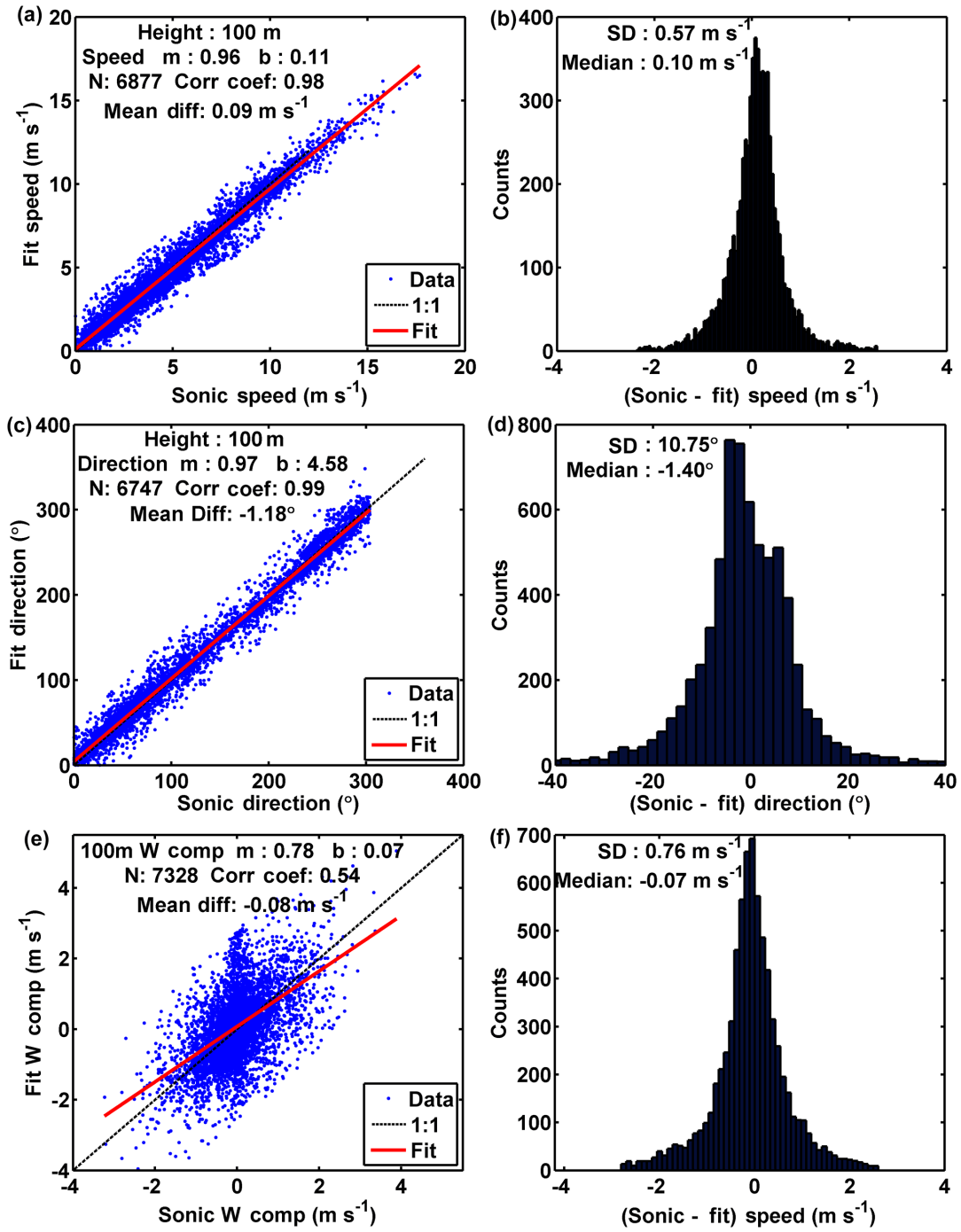

Figure 9. Comparison of the $(\mathbf{a}, \mathbf{b})$ wind speed, $(\mathbf{c}, \mathbf{d})$ wind direction and $(\mathbf{e}, \mathbf{f})$ vertical velocity measurements from the SCB technique with the measurements made by the sonic anemometer.

plained in the previous section. The main difference between the VTS measurement strategy and the SCB strategy is the amount of time buffer allowed to make overlapping LOS measurements. In the VTS strategy, each lidar performed a stare scan for $25 \mathrm{~s}$ at each measurement location, while it was $5 \mathrm{~s}$ for the SCB strategy. Therefore, there was less time to ensure measurement overlap in the SCB strategy and it is expected to have slightly higher uncertainty in wind-field measurement.

\subsection{Uncoordinated virtual tower technique (UVT)}

The measurements made from the UVT technique were compared to the $15 \mathrm{~s}$ averaged sonic anemometer measurements at all six levels of the BAO tower. Figure 10 shows that the measurements from the UVT technique have good agreement with the sonic anemometer measurements with correlation coefficients of 0.95 and 0.99 for wind speed and wind direction, respectively. The standard deviation of the differences $\left(0.65 \mathrm{~m} \mathrm{~s}^{-1}\right.$ for horizontal wind speed and $11.62^{\circ}$ for the horizontal wind direction) were found to be slightly higher compared to the VTS technique. This increase is expected as the LOS velocity measurements are no longer coordinated in time, which leads to an increase in measurement uncertainty due to non-stationarity of the atmosphere. The vertical velocity measurements made using this technique for heights $150 \mathrm{~m}$ and above show a similar skill as the VTS technique, albeit with a slightly lower correlation coefficient of 0.77 . In addition, comparison of the vertical velocity measurements made at the $50 \mathrm{~m}$ level (see Fig. 11) shows that the UVT technique has no skill in making accurate measurements due to the lower elevation angles involved. 

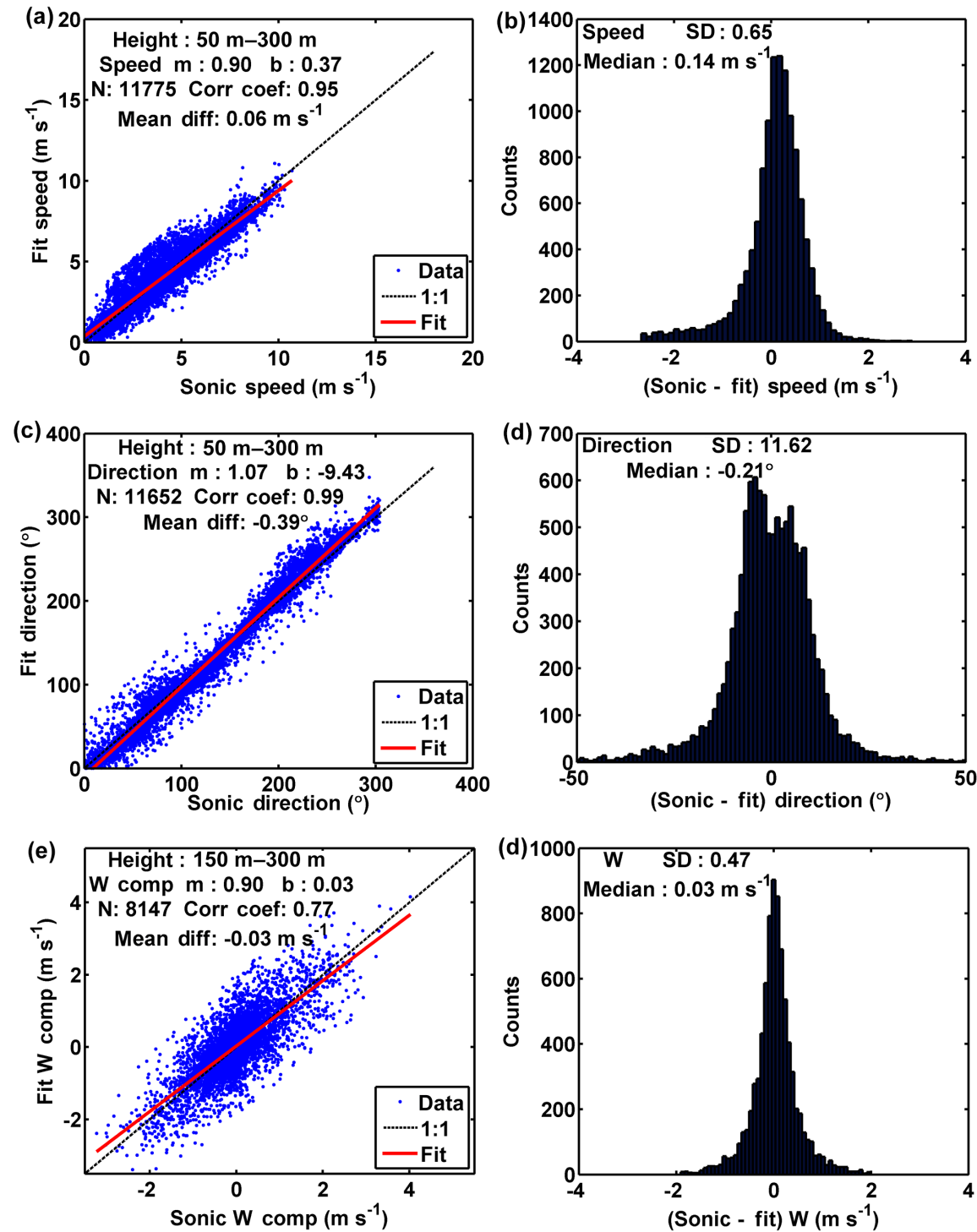

Figure 10. Comparison of the $(\mathbf{a}, \mathbf{b})$ wind speed, $(\mathbf{c}, \mathbf{d})$ wind direction and $(\mathbf{e}, \mathbf{f})$ vertical velocity measurements from the uncoordinated virtual tower technique with the measurements made by the sonic anemometer.
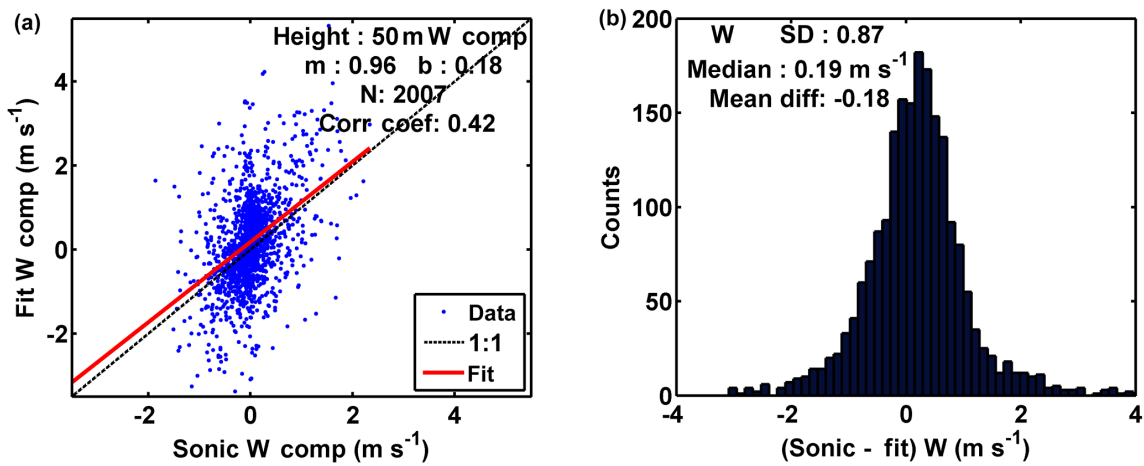

Figure 11. Comparison of the vertical velocity measurements from uncoordinated virtual tower technique at the $50 \mathrm{~m}$ level with the sonic anemometer measurements. 

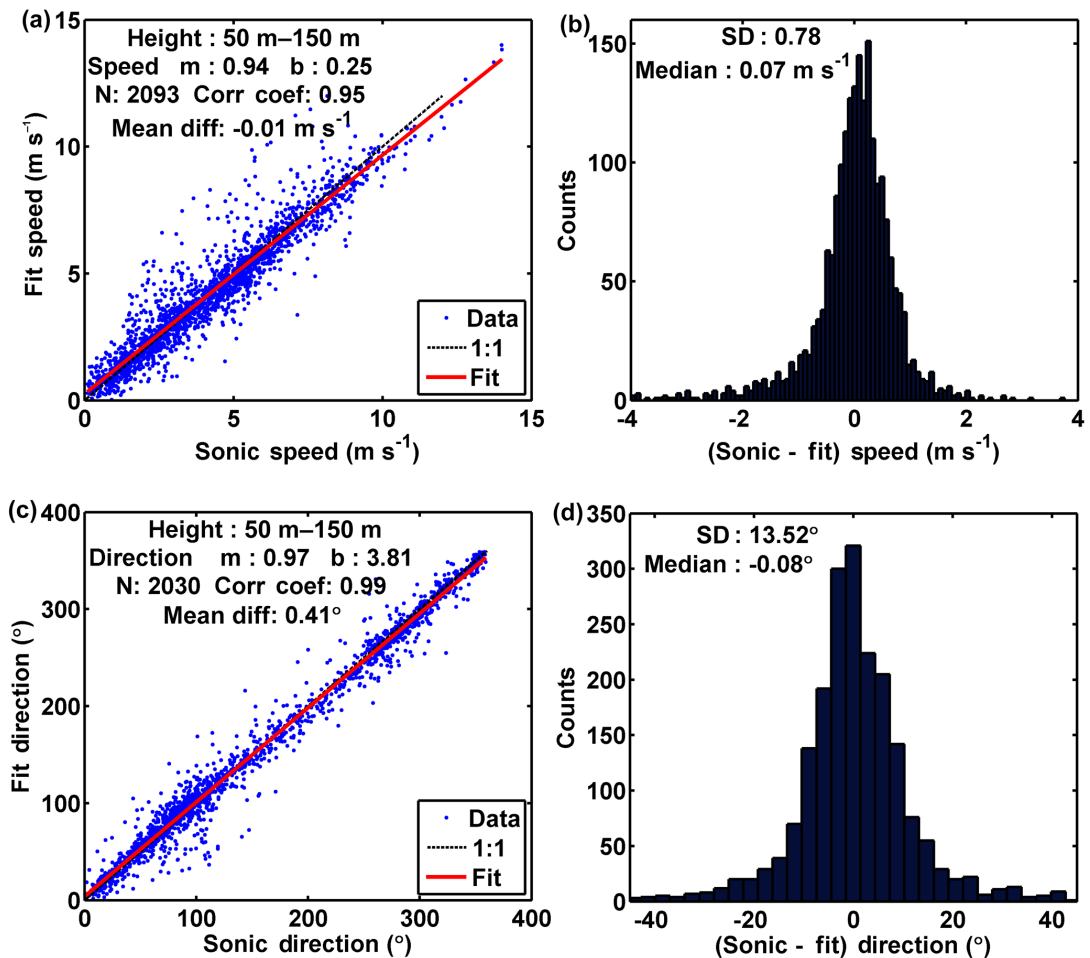

Figure 12. Comparison of the (a, b) wind speed and ( $(\mathbf{c}, \mathbf{d})$ wind direction measurements from the uncoordinated volume scan technique with the measurements made by the sonic anemometer.
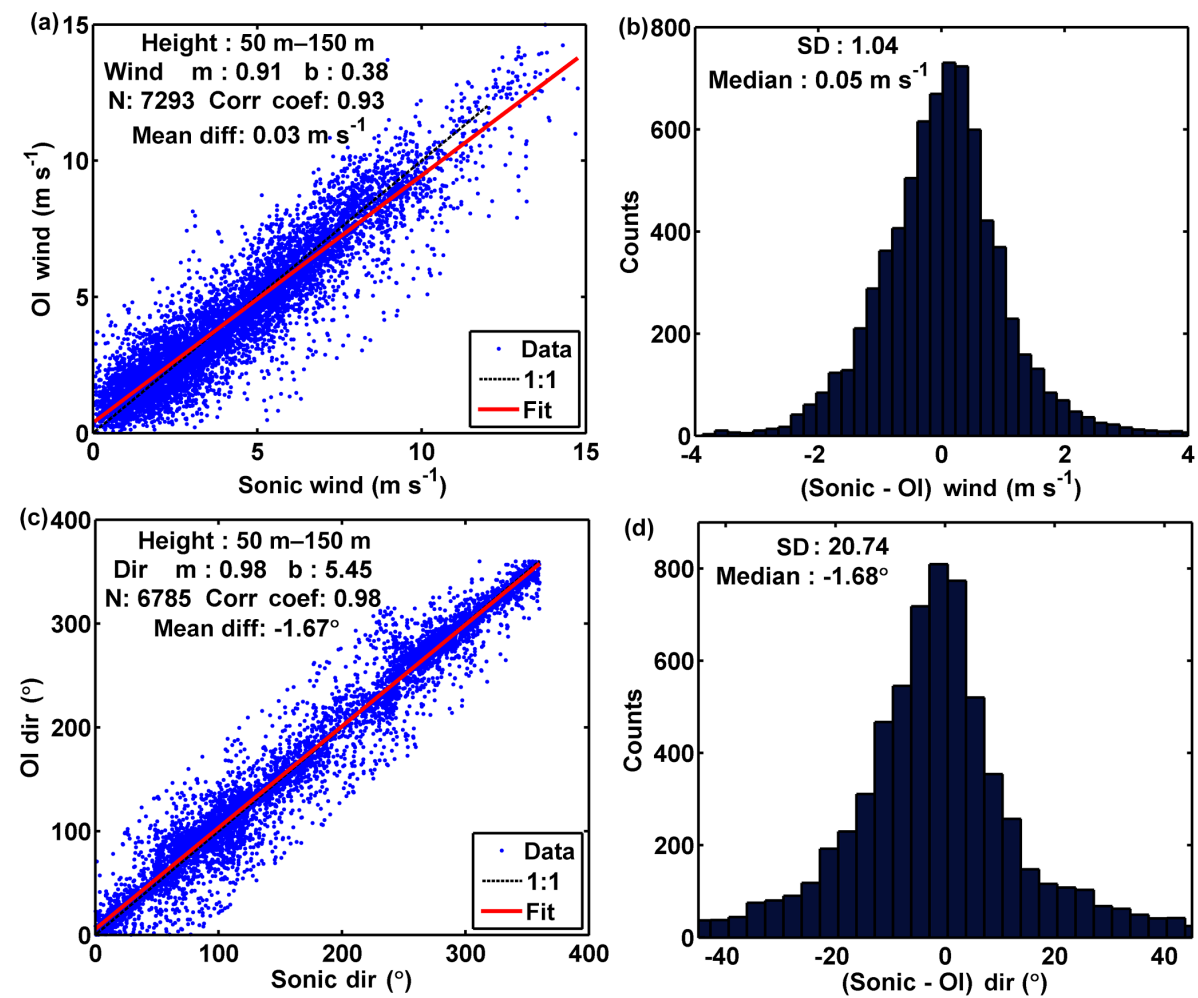

Figure 13. Comparison of the $(\mathbf{a}, \mathbf{b})$ wind speed and $(\mathbf{c}, \mathbf{d})$ wind direction measurements from the single-Doppler OI technique with the measurements made by the sonic anemometer. 


\subsection{Uncoordinated volume scan}

The uncoordinated volume scan strategy further relaxes the requirement for each lidar to make simultaneous LOS measurements at each measurement location and instead uses all LOS velocity measurements from all Doppler lidars that fall within the grid volume and are within a given time window (in this case $5 \mathrm{~min}$ ) to make a wind-field measurement. Comparison of the uncoordinated volume scan measurements with $5 \mathrm{~min}$ averaged sonic anemometer measurements (at three levels from 50 to $150 \mathrm{~m}$ ) shows good correlation coefficients of 0.95 and 0.99 for wind speed and direction, respectively (see Fig. 12).

The standard deviation of the differences between the uncoordinated volume scan measurements and sonic anemometer measurements $\left(0.78 \mathrm{~m} \mathrm{~s}^{-1}\right.$ for horizontal wind speed and $13.52^{\circ}$ for horizontal wind direction) is higher compared to the differences reported for the coordinated measurement techniques. The higher uncertainties could be due to nonstationarity of the winds over the measurement accumulation period, the effect of which is expected to be much larger compared to the case of UVT technique due to the longer measurement accumulation period. Another factor (which is related to the non-stationarity of the wind) is the less representative LOS velocity statistics, which is due to the fact that since each lidar does not spend enough time measuring within each grid cell. As a result, the mean of the LOS velocity measurements from each lidar is not representative of the mean velocity over which the wind retrieval is made.

\subsection{Single-Doppler OI technique}

The OI technique allows retrieval of 2-D wind field over conical scans without applying the assumption of horizontal homogeneity of the wind. The OI technique was applied to the sector scans performed by each lidar in the uncoordinated volume scan technique. Each sector scan took $30 \mathrm{~s}$ to complete, and hence the OI retrieval is compared to $30 \mathrm{~s}$ averaged sonic anemometer measurement shown in Fig. 13. The retrievals from the OI technique agree with the sonic anemometer measurements quite well with correlation coefficients of 0.93 and 0.98 for wind speed and wind direction, respectively. The standard deviation of the differences $\left(1.04 \mathrm{~m} \mathrm{~s}^{-1}\right.$ for horizontal wind speed and $20.74^{\circ}$ for horizontal wind direction) are higher, compared to the uncoordinated volume scan technique.

\section{Discussion of results}

The precision of the wind measurement (defined as the standard deviation of the differences between the Doppler measurement and the sonic anemometer measurement) obtained from the various Doppler lidar techniques can now be compared. The measurement precision reported for each of the techniques is related to the time it takes to perform one mea- surement and hence the time average used to evaluate the technique. This method is chosen so that the inherent tradeoff between spatial coverage and temporal resolution is clear.

Figure 14 shows the comparison of the uncertainties for the LOS velocity as well as the estimates of the horizontal wind speed and direction from the various measurement techniques. As seen from Fig. 14, the uncertainty in the LOS velocity (from comparison with sonic anemometer) is $0.5 \mathrm{~m} \mathrm{~s}^{-1}$. It is observed that with an averaging time of $5 \mathrm{~s}$ for the VTS method, the uncertainty does not increase compared to the sonic-derived LOS velocity uncertainty. The most probable reason the precision of the VTS technique is found to be the highest (compared to other velocity retrieval techniques presented here) is due to the fact that the three $200 \mathrm{~S}$ lidars made simultaneous measurements within the common volume and thus relying less heavily on the assumption of stationarity of the atmosphere or spatial homogeneity. Increasing the measurement complexity and spatial coverage either through faster scanning or relaxing the requirement of temporal coordination increases the measurement uncertainty as well. The reasons for this could be two-fold. First, since the measurements are not temporally synchronized, the non-stationarity of the atmosphere increases the uncertainty in the measurement; secondly, due to faster scanning, there are fewer LOS velocity measurements within each measurement volume resulting in nonrepresentative LOS velocity statistics that result in a poorer estimation of the mean wind. The latter issue is expected to be less dominant in simpler uncoordinated strategies such as the UVT and more dominant in strategies involving covering large spatial extents such as the uncoordinated volume scan. While the single-Doppler OI does not require complex scanning technique, it requires certain assumptions as part of the retrieval process (Choukulkar et al., 2012) and hence increases the measurement uncertainty.

The uncertainty estimates in Fig. 14 (as compared to a sonic anemometer) allows one to determine the appropriate measurement technique for a given application. For example, the VTS technique allows making accurate high temporal resolution velocity measurements that can be useful for measuring not only mean winds but also turbulence and momentum fluxes (for example Fuertes et al., 2014). While UTVs are not as suited to measure turbulence, they allow measurement of the mean wind with only slightly higher uncertainty, but better temporal resolution, while not requiring significant effort in coordinating multiple Doppler lidar scanners. Similarly for measuring winds over large spatial domains and capturing the spatial heterogeneity information, the uncoordinated multi-Doppler volume scans allow measuring wind fields over a 3-D volumes more accurately but require multiple lidars scanning in optimized scan patterns. The OI technique, although less accurate than the multiDoppler approach, covers larger spatial extents in the same time and requires only one lidar. 
(a) 1.2

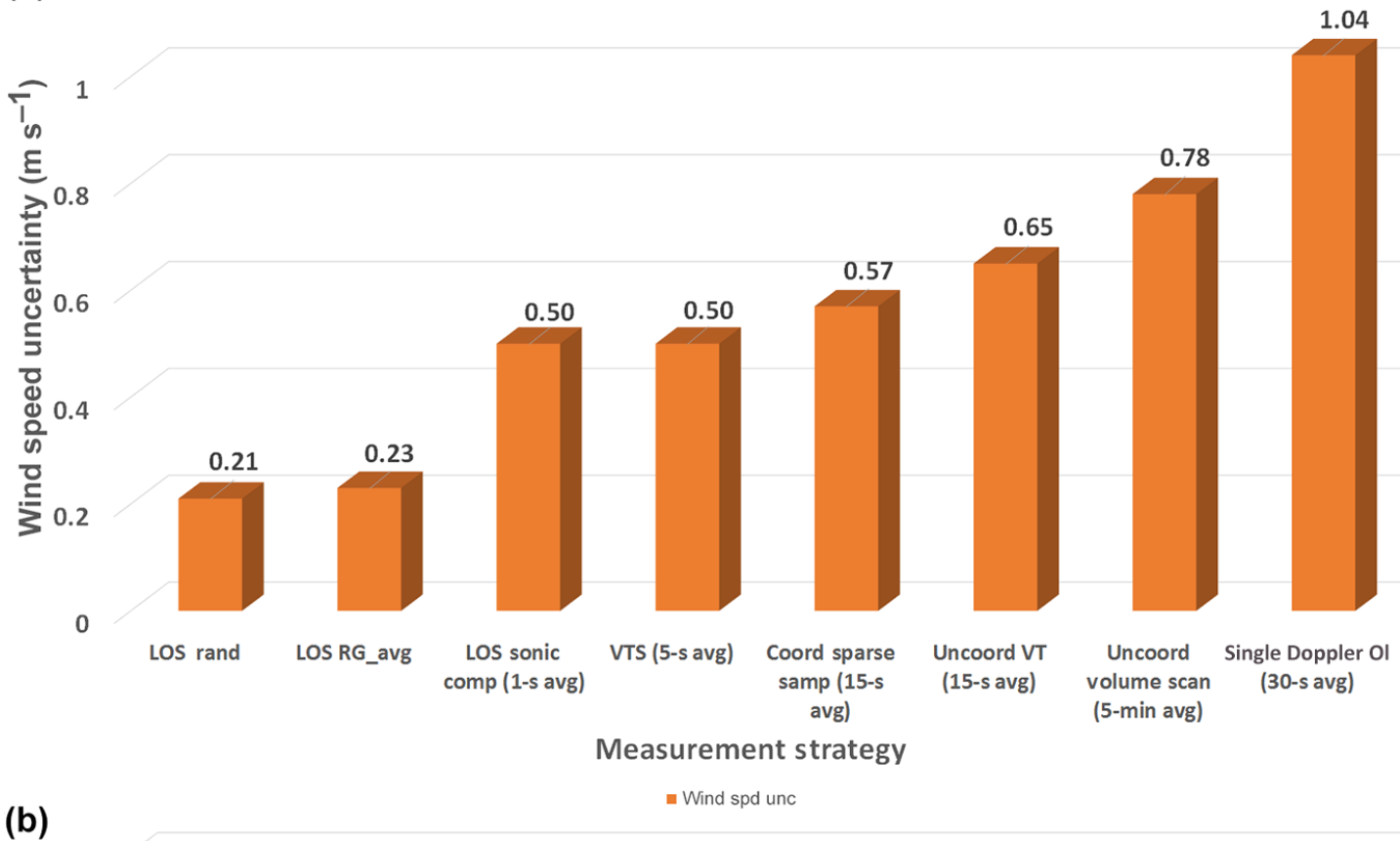

(b)

25

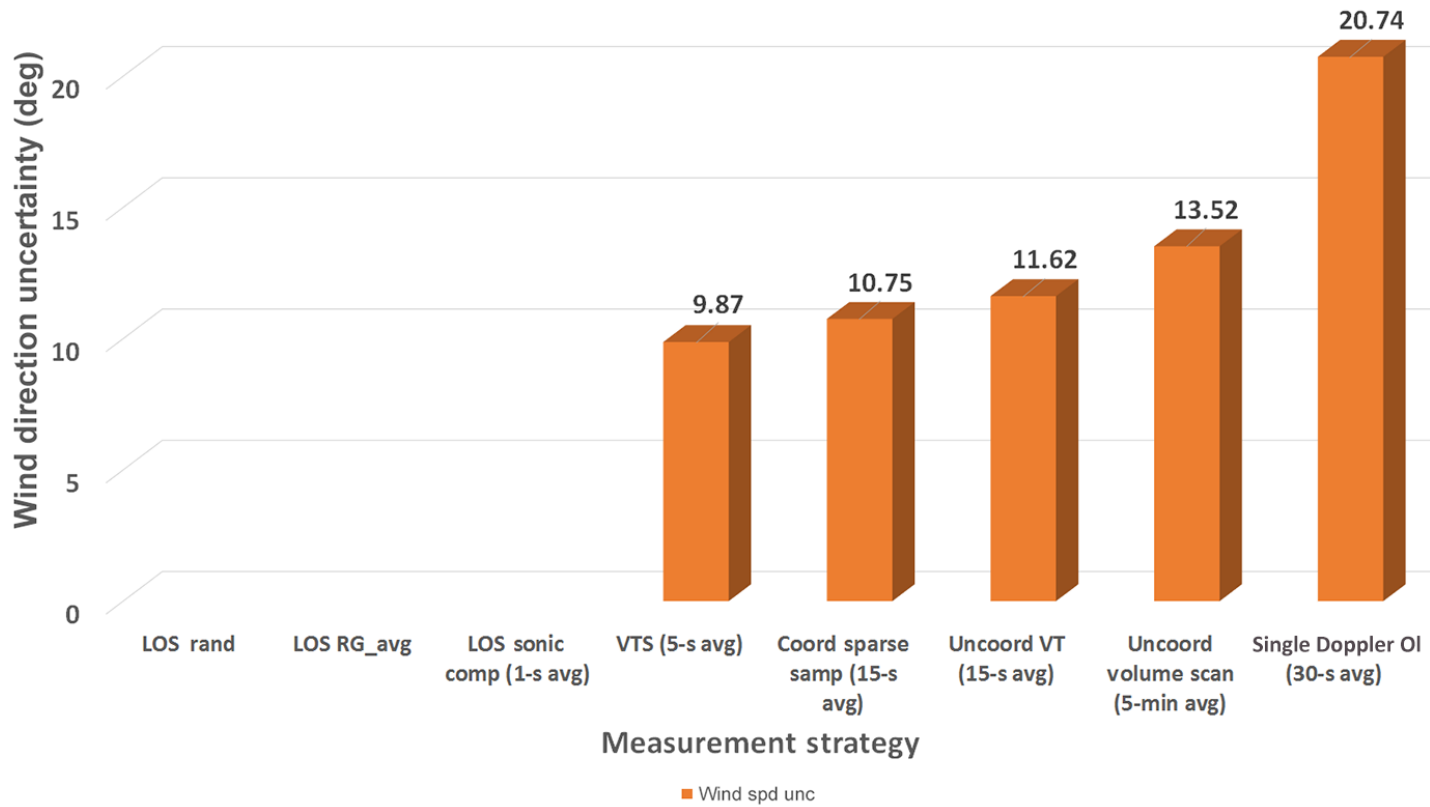

Figure 14. Measurement uncertainties for (a) horizontal wind speed and (b) horizontal wind direction estimated for the different measurement strategies investigated.

\section{Effect of stability}

The precision of wind measurements is also evaluated in various stability conditions. The stability is defined using hourly averaged virtual potential temperature gradient between the $50 \mathrm{~m}$ level and the $300 \mathrm{~m}$ level using both the tower measurements and radiometer measurements (Bianco et al., 2016).
Conditions were determined to be stable for positive gradient of the virtual potential temperature and unstable for a negative gradient of the virtual potential temperature.

The lidar wind speed measurements are found to be slightly more precise during stable conditions compared to unstable conditions (see Fig. 15). The higher uncertainties observed during unstable conditions might be due to the fact 


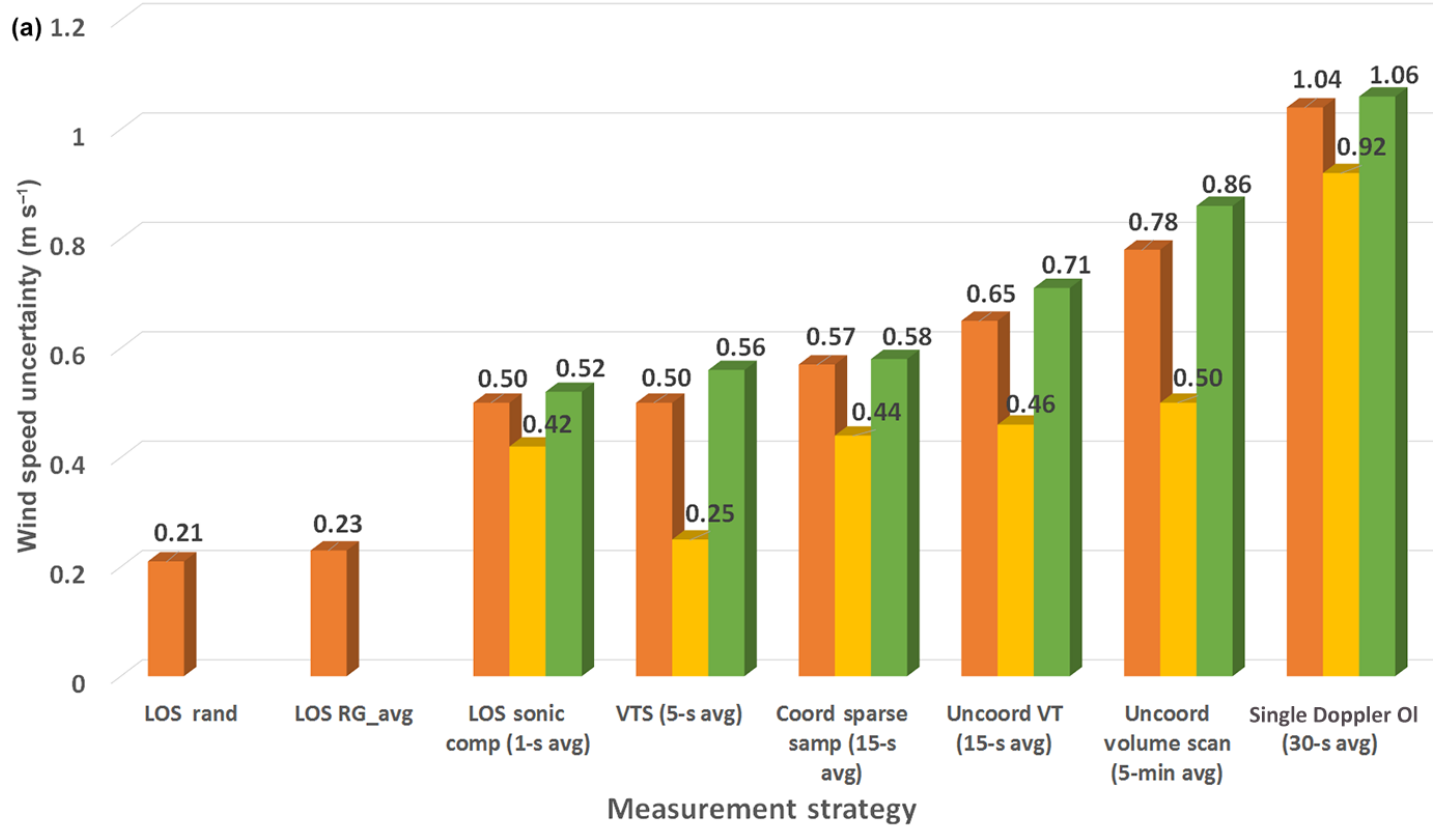

(b) 30

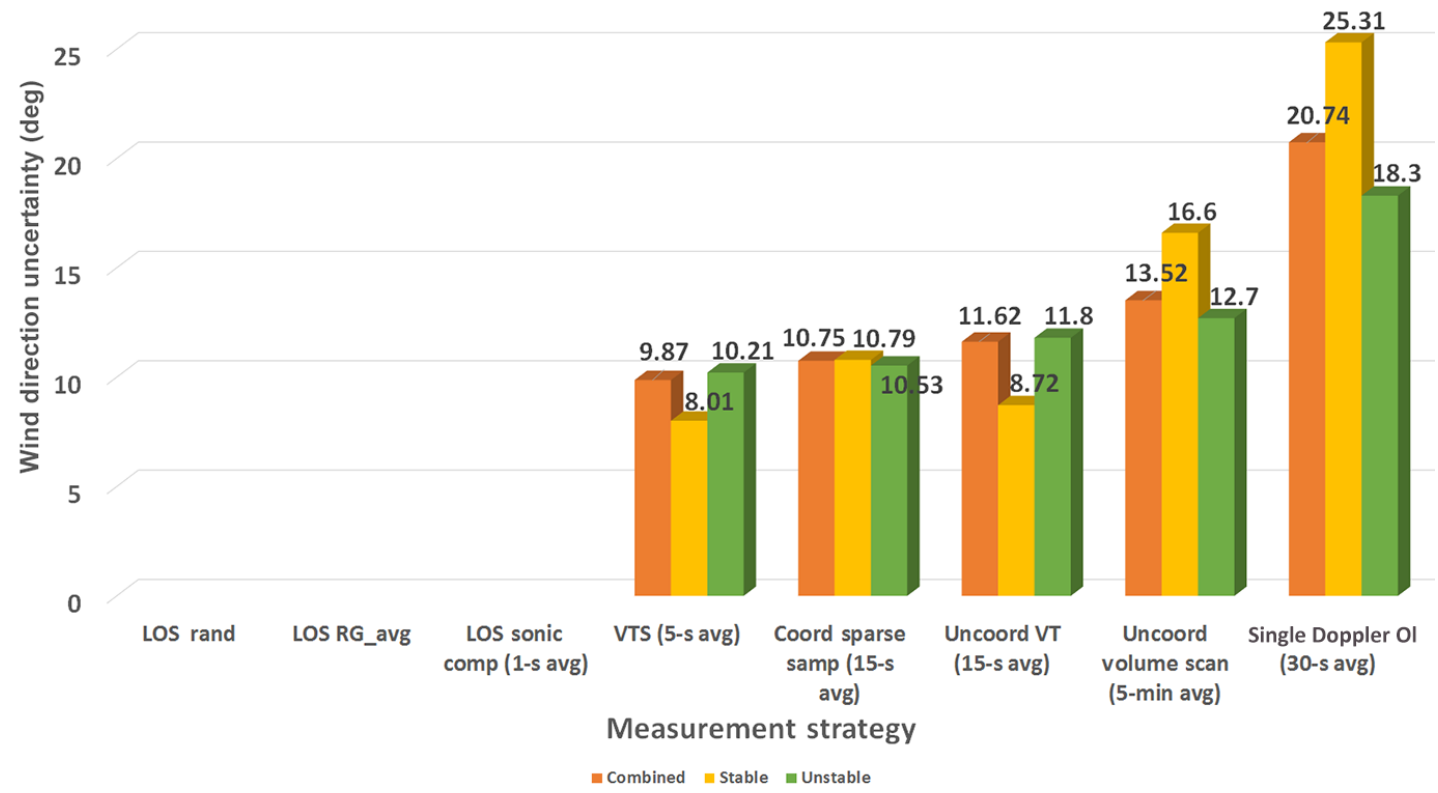

Figure 15. Measurement uncertainty as a function of stability for (a) horizontal wind speed and (b) horizontal wind direction.

that unstable conditions show higher variability than stable conditions, which might lead to higher level of uncertainty. However, no consistent pattern emerges for the effect of stability on wind direction uncertainty. This might be due to the fact that all the stable conditions examined here were accompanied by low wind conditions, which usually leads to higher variability in wind direction, while the unstable conditions had higher wind speeds. As a result, the wind direction uncertainty during stable conditions is found to be higher. It is clear from Fig. 15 that stability and spatial variability do have a significant impact on the measurement uncertainty.

\section{Conclusions}

Scanning Doppler lidars are powerful tools that enable measuring atmospheric flows using various configuration of single and multi-Doppler techniques. An important aspect of proper interpretation of the measurements made using 
Doppler lidars is understanding the inherent uncertainties associated with the corresponding measurement technique. In this paper, the uncertainties associated with Doppler lidar measurements were quantified starting with the uncertainties due to random noise and pulse averaging to uncertainties associated with single- and multi-Doppler measurement techniques.

It was found that as complexity of the measurement technique and/or the spatial coverage of measurements made increased, the uncertainty in the wind measurement also increased. For multi-Doppler measurements, the magnitude of uncertainty was associated with ability to make coordinated measurements. Measurements made using accurate coordinated scanning resulted in lower uncertainties compared to measurements from temporally uncoordinated scanning. This result is expected due to the non-stationarity of the atmosphere, sampling error in LOS velocity statistics and presence of spatial variability in the wind field. As a result, the coordinated VTS techniques resulted in the lowest measurement uncertainty, while the single-Doppler OI technique resulted in the highest measurement uncertainty (compared to multi-Doppler techniques), but also had the largest spatial coverage at high update rates and is less expensive as a result of requiring only one lidar.

The results illustrate the tradeoff between making highly precise measurements at one location versus accepting a lower precision but covering larger spatial extents. Although the magnitude of the uncertainties for the various measurement techniques presented in this paper might not be reproducible at other locations and under different wind conditions, the trends observed should be similar. This quantification of the uncertainty as a function of measurement technique allows proper selection of measurement strategy given the goals of the experiment and interpretation of the measurements made using those techniques.

\section{Data availability}

The data from all the instruments deployed during the XPIA field campaign are now available at DOE's Data Access Portal (DAP) located at https://a2e.pnnl.gov/data (Lundquist et al., 2016c). Access to the general public has been open since 1 April 2016. In order to access the data, users need to create an account on the website given above. For further inquiries please contact either Julie Lundquist (julie.lundquist@ colorado.edu) or James Wilczak (james.m.wilczak@noaa.gov).

Acknowledgement. The authors acknowledge the funding for this work provided by the US Department of Energy, Office of Energy Efficiency and Renewable Energy and by NOAA's Earth System Research Laboratory. The authors also acknowledge contributions of numerous individuals and organization who assisted with the field deployment including Bruce Bartram,
Duane Hazen, Tom Ayers, Jesse Leach, Paul Johnston, Lefthand Water District, Erie High School and the St. Vrain School District. We also express our appreciation to NOAA/Earth Systems Research Laboratory/Physical Sciences Division for supporting the instrumentation at the BAO facility. We express appreciation to the National Science Foundation for supporting the CABL deployments (https://www.eol.ucar.edu/field_projects/cabl) of the tower instrumentation. NREL is a national laboratory of the US Department of Energy, Office of Energy Efficiency and Renewable Energy, operated by the Alliance for Sustainable Energy, LLC.

Edited by: A. Clifton

Reviewed by: two anonymous referees

\section{References}

Banta, R. M., Pichugina, Y. L., Brewer, W. A., Lundquist, J. K., Kelley, N. D., Sandberg, S. P., Alvarez II, R. J., Hardesty, R. M., and Weickmann, A. M.: 3D Volumetric Analysis of Wind Turbine Wake Properties in the Atmosphere Using HighResolution Doppler Lidar, J. Atmos. Ocean. Tech., 32, 904-914, doi:10.1175/JTECH-D-14-00078.1, 2015.

Barlow, J. F., Dunbar, T. M., Nemitz, E. G., Wood, C. R., Gallagher, M. W., Davies, F., O'Connor, E., and Harrison, R. M.: Boundary layer dynamics over London, UK, as observed using Doppler lidar during REPARTEE-II, Atmos. Chem. Phys., 11, 2111-2125, doi:10.5194/acp-11-2111-2011, 2011.

Berg, J., Vasiljevíc, N., Kelly, M., Lea, G., and Courtney, M.: Addressing Spatial Variability of Surface-Layer Wind with LongRange WindScanners, J. Atmos. Ocean. Tech., 32, 518-527, doi:10.1175/JTECH-D-14-00123.1, 2015.

Bianco, L., Friedrich, K., Wilczak, J., Hazen, D., Wolfe, D., Delgado, R., Oncley, S., and Lundquist, J. K.: Assessing the accuracy of microwave radiometers and radio acoustic sounding systems for wind energy applications, Atmos. Meas. Tech. Discuss., doi:10.5194/amt-2016-321, in review, 2016.

Bingöl, F., Mann, J., and Foussekis, D.: Conically scanning lidar error in complex terrain, Meteorol. Z., 18, 189-195, doi:10.1127/0941-2948/2009/0368, 2009.

Browning, K. A. and Wexler, R.: The determination of kinematic properties of a wind field using Doppler radar, J. Appl. Meteorol., 7, 105-113, 1968.

Calhoun, R., Heap, R., Princevac, M., Newsom, R., Fernando, H., and Ligon, D.: Virtual towers using coherent Doppler lidar during the Joint Urban 2003 dispersion experiment, J. Appl. Meteorol. Clim., 45, 1116-1126, 2006.

Chan, P. W. and Shao, A. M.: Depiction of complex airflow near Hong Kong International Airport using a Doppler LIDAR with a two-dimensional wind retrieval technique, Meteorol. Z., 16, 491504, 2007.

Cherukuru, N. W., Calhoun, R., Lehner, M., Hoch, S. W., and Whiteman, C. D.: Instrument configuration for dual-Doppler lidar coplanar scans: METCRAX II, J. Appl. Remote Sens., 9, 096090, doi:10.1117/1.JRS.9.096090, 2015.

Choukulkar, A.: Coherent Doppler Lidar for Boundary Layer Studies and Wind Energy, in ASU Electronic Dissertations and Theses, Arizona State University, available at: http://hdl.handle.net/ 2286/R.I.16449 (last access: 9 January 2016), 2013. 
Choukulkar, A., Calhoun, R., Billings, B., and Doyle, J. D.: A modified optimal interpolation technique for vector retrieval for coherent Doppler lidar, Geosci. Remote Sens. Lett., 9, 1132-1136, 2012.

Collier, C. G., Davies, F., Bozier, K. E., Holt, A. R., Middleton, D. R., Pearson, G. N., Siemen, S., Willetts, D. V., Upton, G. J. G., and Young, R. I.: Dual-Doppler Lidar Measurements for Improving Dispersion Models, B. Am. Meteor. Soc., 86, 825-838, doi:10.1175/BAMS-86-6-825, 2005.

Damian, T., Wieser, A., Träumner, K., Corsmeier, U., and Kottmeier, C.: Nocturnal Low-level Jet Evolution in a Broad Valley Observed by Dual Doppler Lidar, Meteorol. Z., 305-313, 2014.

Drechsel, S., Mayr, G. J., Chong, M., Weissmann, M., Dörnbrack, A., and Calhoun, R.: Three-Dimensional Wind Retrieval: Application of MUSCAT to Dual-Doppler Lidar, J. Atmos. Ocean. Tech., 26, 635-646, doi:10.1175/2008JTECHA1115.1, 2009.

Fernando, H. J. S., Pardyjak, E. R., Di Sabatino, S., Chow, F. K., De Wekker, S. F. J., Hoch, S. W., Hacker, J., Pace, J. C., Pratt, T., $\mathrm{Pu}$, Z., Steenburgh, W. J., Whiteman, C. D., Wang, Y., Zajic, D., Balsley, B., Dimitrova, R., Emmitt, G. D., Higgins, C. W., Hunt, J. C. R., Knievel, J. C., Lawrence, D., Liu, Y., Nadeau, D. F., Kit, E., Blomquist, B. W., Conry, P., Coppersmith, R. S., Creegan, E., Felton, M., Grachev, A., Gunawardena, N., Hang, C., Hocut, C. M., Huynh, G., Jeglum, M. E., Jensen, D., Kulandaivelu, V., Lehner, M., Leo, L. S., Liberzon, D., Massey, J. D., McEnerney, K., Pal, S., Price, T., Sghiatti, M., Silver, Z., Thompson, M., Zhang, H., and Zsedrovits, T.: The MATERHORN: Unraveling the Intricacies of Mountain Weather, B. Am. Meteor. Soc., 96, 1945-1967, doi:10.1175/BAMS-D-13-00131.1, 2015.

Fuertes, F. C., Iungo, G. V., and Porté-Agel, F.: 3D Turbulence Measurements Using Three Synchronous Wind Lidars: Validation against Sonic Anemometry, J. Atmos. Ocean. Tech., 31, 15491556, doi:10.1175/JTECH-D-13-00206.1, 2014.

Gunter, W. S., Schroeder, J. L., and Hirth, B. D.: Validation of Dual-Doppler Wind Profiles with in situ Anemometry, J. Atmos. Ocean. Tech., 32, 943-960, doi:10.1175/JTECH-D-14-00181.1, 2015.

Hill, M., Calhoun, R., Fernando, H. J. S., Wieser, A., Dörnbrack, A., Weissmann, M., Mayr, G., and Newsom, R.: Coplanar Doppler lidar retrieval of rotors from T-REX, J. Atmos. Sci., 67, 713-729, 2010.

Kaimal, J. C. and Gaynor, J. E.: The Boulder Atmospheric Observatory, J. Clim. Appl. Meteorol., 22, 863-880, doi:10.1175/15200450(1983)022<0863:TBAO>2.0.CO;2, 1983.

Käsler, Y., Rahm, S., Simmet, R., and Kühn, M.: Wake Measurements of a Multi-MW Wind Turbine with Coherent Long-Range Pulsed Doppler Wind Lidar, J. Atmos. Ocean. Tech., 27, 15291532, doi:10.1175/2010JTECHA1483.1, 2010.

Klein, P., Bonin, T. A., Newman, J. F., Turner, D. D., Chilson, P. B., Wainwright, C. E., Blumberg, W. G., Mishra, S., Carney, M., Jacobsen, E. P., Wharton, S., and Newsom, R. K.: LABLE: A Multi-Institutional, Student-Led, Atmospheric Boundary Layer Experiment, B. Am. Meteor. Soc., 96, 17431764, doi:10.1175/BAMS-D-13-00267.1, 2015.

Krishnamurthy, R., Choukulkar, A., Calhoun, R., Fine, J., Oliver, A., and Barr, K. S.: Coherent Doppler lidar for wind farm characterization, Wind Energy, 16, 189-206, 2013.
Lenschow, D. H., Wulfmeyer, V., and Senff, C.: Measuring secondthrough fourth-order moments in noisy data, J. Atmos. Ocean. Tech., 17, 1330-1347, 2000.

Lundquist, J. K., Churchfield, M. J., Lee, S., and Clifton, A.: Quantifying error of lidar and sodar Doppler beam swinging measurements of wind turbine wakes using computational fluid dynamics, Atmos. Meas. Tech., 8, 907-920, doi:10.5194/amt-8-9072015, 2015.

Lundquist, J. K., Wilczak, J. M., Ashton, R., Bianco, L., Brewer, W. A., Choukulkar, A., Clifton, A., Debnath, M., Delgado, R., Friedrich, K., Gunter, S., Hamidi, A., Iungo, G. V., Kaushik, A., Kosović, B., Langan, P., Lass, A., Lavin, E., Lee, J. C.-Y., McCaffrey, K. L., Newsom, R. K., Noone, D. C., Oncley, S. P., Quelet, P. T., Sandberg, S. P., Schroeder, J. L., Shaw, W. J., Sparling, L., St. Martin, C., St. Pe, A., Strobach, E., Tay, K., Vanderwende, B. J., Weickmann, A., Wolfe, D., and Worsnop, R.: Assessing state-of-the-art capabilities for probing the atmospheric boundary layer: the XPIA field campaign, B. Am. Meteor. Soc., doi:10.1175/BAMS-D-15-00151.1, online first, 2016a.

Lundquist, J. K., Wilczak, J. M., Ashton, R., Bianco, L., Brewer, W. A., Choukulkar, A., Clifton, A., Debnath, M., Delgado, R., Friedrich, K., Gunter, S., Hamidi, A., Iungo, G. V., Kaushik, A., Kosović, B., Langan, P., Lass, A., Lavin, E., Lee, J. C.-Y., McCaffrey, K. L., Newsom, R. K., Noone, D. C., Oncley, S. P., Quelet, P. T., Sandberg, S. P., Schroeder, J. L., Shaw, W. J., Sparling, L., St. Martin, C., St. Pe, A., Strobach, E., Tay, K., Vanderwende, B. J., Weickmann, A., Wolfe, D., and Worsnop, R.: Assessing state-of-the-art capabilities for probing the atmospheric boundary layer: the XPIA field campaign, National Renewable Energy Laboratory (NREL), Golden, CO, 2016b.

Lundquist, J. K., Wilczak, J. M., Ashton, R., Bianco, L., Brewer, W. A., Choukulkar, A., Clifton, A., Debnath, M., Delgado, R., Friedrich, K., Gunter, S., Hamidi, A., Iungo, G. V., Kaushik, A., Kosović, B., Langan, P., Lass, A., Lavin, E., Lee, J. C.-Y., McCaffrey, K. L., Newsom, R. K., Noone, D. C., Oncley, S. P., Quelet, P. T., Sandberg, S. P., Schroeder, J. L., Shaw, W. J., Sparling, L., St. Martin, C., St. Pe, A., Strobach, E., Tay, K., Vanderwende, B. J., Weickmann, A., Wolfe, D., and Worsnop, R.: XPIA, Pacific Northwest National Laboratory, Department of Energy, available at: https://a2e.pnnl.gov/data (last access: 18 January 2017), 2016c.

Mann, J., Cariou, J.-P., Courtney, M. S., Parmentier, R., Mikkelsen, T., Wagner, R., Lindelöw, P., Sjöholm, M., and Enevoldsen, K.: Comparison of 3D turbulence measurements using three staring wind lidars and a sonic anemometer, Meteorol. Z., 18, 135-140, doi:10.1127/0941-2948/2009/0370, 2009.

McCaffrey, K., Quelet, P., Choukulkar, A., Wilczak, J. M., Wolfe, D. E., Oncley, S., Brewer, A., Debnath, M., Ashton, R., Iungo, G. V., and Lundquist, J. K.: Identification of Tower Wake Distortions Using Sonic Anemometer and Lidar Measurements, Atmos. Meas. Tech. Discuss., doi:10.5194/amt-2016-179, in review, 2016.

Mikkelsen, T.: Lidar-based research and innovation at DTU wind energy-a review, in Journal of Physics: Conference Series, vol. 524, p. 012007, IOP Publishing, available at: http://iopscience.iop.org/article/10.1088/1742-6596/524/1/ 012007/meta (last access: 22 August 2016), 2014.

Mikkelsen, T., Mann, J., Courtney, M., and Sjöholm, M.: Windscanner: 3-D wind and turbulence measurements from three steerable 
doppler lidars, in IOP Conference Series: Earth and Environmental Science, 1, U148-U156, Institute of Physics Publishing Ltd., 2008.

Newman, J. F., Bonin, T. A., Klein, P. M., Wharton, S., and Newsom, R. K.: Testing and validation of multi-lidar scanning strategies for wind energy applications, Wind Energy, 19, 2239-2254, doi:10.1002/we.1978, 2016.

Newsom, R., Calhoun, R., Ligon, D., and Allwine, J.: Linearly organized turbulence structures observed over a suburban area by dual-Doppler lidar, Bound.-Layer Meteorol., 127, 111-130, 2008.

Newsom, R. K., Berg, L. K., Shaw, W. J., and Fischer, M. L.: Turbine-scale wind field measurements using dual-Doppler lidar, Wind Energy, 18, 219-235, doi:10.1002/we.1691, 2015.

Simley, E., Angelou, N., Mikkelsen, T., Sjöholm, M., Mann, J., and Pao, L. Y.: Characterization of wind velocities in the upstream induction zone of a wind turbine using scanning continuous-wave lidars, J. Renew. Sustain. Energy, 8, 013301, doi:10.1063/1.4940025, 2016.

Stawiarski, C., Träumner, K., Knigge, C., and Calhoun, R.: Scopes and challenges of dual-Doppler lidar wind measurements - an error analysis, J. Atmos. Ocean. Tech., 30, 2044-2062, 2013.

Strauch, R. G., Merritt, D. A., Moran, K. P., Earnshaw, K. B., and De Kamp, D. V.: The Colorado Wind-Profiling Network, J. Atmos. Ocean. Tech., 1, 37-49, doi:10.1175/15200426(1984)001<0037:TCWPN>2.0.CO;2, 1984.

Träumner, K., Damian, T., Stawiarski, C., and Wieser, A.: Turbulent structures and coherence in the atmospheric surface layer, Bound.-Layer Meteorol., 154, 1-25, 2015.
Vanderwende, B. J., Lundquist, J. K., Rhodes, M. E., Takle, E. S., and Irvin, S. L.: Observing and simulating the summertime lowlevel jet in central Iowa, available at: http://journals.ametsoc.org/ doi/abs/10.1175/MWR-D-14-00325.1 (last access: 24 October 2015), Mon. Weather Rev., 2015.

Vasiljević, N., Lea, G., Courtney, M., Cariou, J.-P., Mann, J., and Mikkelsen, T.: Long-Range WindScanner System, Remote Sens., 8, 1-24, doi:10.3390/rs8110896, 2016.

Vollmer, L., van Dooren, M., Trabucchi, D., Schneemann, J., Steinfeld, G., Witha, B., Trujillo, J., and Kühn, M.: First comparison of LES of an offshore wind turbine wake with dual-Doppler lidar measurements in a German offshore wind farm, J. Phys. Conf. Ser., 625, 012001, doi:10.1088/1742-6596/625/1/012001, 2015.

Waldteufel, P. and Corbin, H.: On the analysis of single-Doppler radar data, J. Appl. Meteorol., 18, 532-542, 1979.

Wang, H., Barthelmie, R. J., Clifton, A., and Pryor, S. C.: Wind Measurements from Arc Scans with Doppler Wind Lidar, J. Atmos. Ocean. Tech., 32, 2024-2040, doi:10.1175/JTECH-D-14$00059.1,2015$.

Wang, Y., Hocut, C. M., Hoch, S. W., Creegan, E., Fernando, H. J. S., Whiteman, C. D., Felton, M., and Huynh, G.: Triple Doppler wind lidar observations during the mountain terrain atmospheric modeling and observations field campaign, J. Appl. Remote Sens., 10, 026015, doi:10.1117/1.JRS.10.026015, 2016. 